\title{
Capital Market Integration and Consumption Risk Sharing over the Long Run
}

Rangvid, Jesper; Santa-Clara, Pedro; Schmeling, Maik

\author{
Document Version \\ Accepted author manuscript \\ Published in: \\ Journal of International Economics
}

DOI:

10.1016/j.jinteco.2016.08.001

Publication date:

2016

License

CC BY-NC-ND

Citation for published version (APA):

Rangvid, J., Santa-Clara, P., \& Schmeling, M. (2016). Capital Market Integration and Consumption Risk Sharing over the Long Run. Journal of International Economics, 103, 27-43. https://doi.org/10.1016/j.jinteco.2016.08.001

Link to publication in CBS Research Portal

\section{General rights}

Copyright and moral rights for the publications made accessible in the public portal are retained by the authors and/or other copyright owners and it is a condition of accessing publications that users recognise and abide by the legal requirements associated with these rights.

\section{Take down policy}

If you believe that this document breaches copyright please contact us (research.lib@cbs.dk) providing details, and we will remove access to the work immediately and investigate your claim.

Download date: 26. Apr. 2023

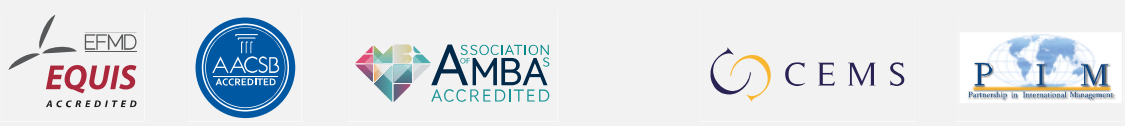




\section{Capital Market Integration and Consumption Risk Sharing over the Long Run}

\section{Jesper Rangvid, Pedro Santa-Clara, and Maik Schmeling}

Journal article (Post print version)

Cite: Capital Market Integration and Consumption Risk Sharing over the Long Run. / Rangvid, Jesper; Santa-Clara, Pedro; Schmeling, Maik. In: Journal of International Economics, Vol. 103, 11.2016, p. 27-43.

DOI: 10.1016/j.jintec0.2016.08.001

Uploaded to Research@CBS: October २०16

(C) 2016. This manuscript version is made available under the CC-BY-NC-ND 4.0 license

http://creativecommons.org/licenses/by-nc-nd/4.0/ 


\title{
Capital Market Integration and Consumption Risk Sharing over the Long Run*
}

\author{
Jesper Rangvid ${ }^{\ddagger}$ \\ Pedro Santa-Clara ${ }^{\ddagger \ddagger}$ \\ Maik Schmeling**
}

August 12, 2016

\footnotetext{
${ }^{*}$ We thank two anonymous referees, Enrique Alberola, Pedro Barroso, Harald Hau, Mathias Hoffmann, Andrew Karolyi, Martin Strieborny, and participants at various conferences and seminars for helpful comments and suggestions.

${ }^{\ddagger}$ Department of Finance, Copenhagen Business School, Solbjerg Plads 3, 2000 Frederiksberg, Denmark. E-mail: jr.fi@cbs.dk.

${ }^{\ddagger}$ Millennium Chair in Finance, Universidade Nova de Lisboa - NOVA School of Business and Economics and NBER, Campus de Campolide, 1099-032 Lisboa, Portugal. E-mail: psc@novasbe.pt.

**Faculty of Finance, Cass Business School, City University London, 106 Bunhill Row, London EC1Y 8TZ, UK. Email: maik.schmeling.1@city.ac.uk.
} 


\title{
Capital Market Integration and Consumption Risk Sharing over the Long Run
}

\begin{abstract}
We empirically investigate time variation in capital market integration and consumption risk sharing using data for 16 countries from 1875 to 2012 . We show that there has been considerable variation over time in the degrees of capital market integration and consumption risk sharing and that higher capital market integration forecasts more consumption risk sharing in the future. This finding is robust to controlling for trade openness and exchange rate volatility as alternative drivers of risk sharing. Finally, we calculate the welfare costs of imperfect consumption risk sharing and find that these costs vary over time, line up with variation in risk sharing, and are quite substantial during periods of low risk sharing.
\end{abstract}

JEL-Classification: F36, F21, E44, G12

Keywords: Market integration, Consumption risk sharing 


\section{Introduction}

A key function of financial markets is that they enable risk sharing among agents. One channel through which risk sharing can occur internationally is via trade in international financial assets. In other words, one prerequisite for international consumption risk sharing is capital market integration. In this paper, we use data for 16 countries spanning approximately 140 years to show that periods with higher levels of capital market integration have been followed by periods with higher levels of consumption risk sharing. We also show that there is no evidence of the reverse effect, i.e. consumption risk sharing does not predict capital market integration. These findings lend credence to the standard textbook model that capital market integration is a prerequisite for risk sharing.

More specifically, according to textbook models (Obstfeld \& Rogoff, 1996, for instance), the resulting equilibrium in an economy where consumers have the same iso-elastic utility functions and capital markets are perfectly integrated is one where consumption risk is perfectly shared and only systematic risk to consumption remains. Despite the textbook model's clear predictions, it has been difficult to verify empirically that consumption risk is shared internationally to the extent that the theoretical models predict, even among developed economies. Obstfeld (1994), Tesar (1995), Lewis (1996, 1999), Sørensen \& Yosha (1998), Sørensen, Yosha \& Østergaard (2002), and Sørensen, Yosha, Wu \& Zhu (2007) all show that consumption risk is not shared as much as would a priori be expected.

In this paper, we provide fresh perspectives to this literature. Our main contribution is that we empirically investigate time-series variation in consumption risk sharing and capital market integration, as well as the interaction between these two key measures, using a long sample period going back to the 19th century. Hence, instead of focusing on capital-market integration and consumption risk sharing since the beginning of the post-Bretton Woods period, as is often done in the literature, we propose to exploit the time-variation in capitalmarket integration that has taken place over the last 140 years and link it to time-variation in consumption risk sharing. Intuitively, testing for a link between risk sharing and inte- 
gration lacks power when looking only at the post-Bretton Woods period - where financial integration and risk sharing have generally been trending up (Lane \& Milesi-Ferretti, 2007) - because there is too little variation in the two variables. Employing periods of high and low financial integration over a longer time span alleviates this problem and allows for a more powerful test of the theoretical link between financial integration and consumption risk sharing. In pursuing this strategy, we take inspiration from the more recent literature that examines financial globalization in a historical perspective, such as Obstfeld \& Taylor (2004) and Schularick \& Steger (2010). ${ }^{1}$

Our approach relies to a large extent on the availability of very long data series for many countries. We collect a comprehensive set of consumption growth rates and returns on financial assets from sixteen countries during the 1875-2012 period. The dataset is a combination of the data in Barro \& Ursua (2008), the DMS international return database by Morningstar, and the Global Financial Data (GFD) database. To the best of our knowledge, we are the first to use such a long sample period to investigate the link between consumption risk sharing and financial market integration.

Our starting point is to show that there has indeed been considerable time-variation in the degree of international capital market integration over the last 140 years. As our measure of market integration, we use the dispersion of equity return across countries, i.e. interpreting a lower degree of return dispersion across markets as indicating a higher degree of equity market integration. To make sure that our results are robust, we also consider alternative measures of integration: one based on return exposures to common (global) factors, and one based on a world CAPM. We find a consistent pattern across these different measures. There are periods, such as those surrounding World-War I and II and during the Bretton Woods regime, where capital markets are not highly integrated, and there are periods where capital markets have been highly integrated, such as before World War I and since the beginning of

\footnotetext{
${ }^{1}$ The benefit of using long-term data like those we use in this paper is that we have more variation in integration and risk sharing compared to using, say, only data for the post Bretton Woods era. However, given the long-run nature of these data, we are naturally limited in the scope of the analysis, e.g. we cannot obtain measures of home bias or similar phenomena for a broad set of countries and a long period of time.
} 
the 1990s.

Next, we investigate whether there is time-variation in consumption risk sharing, too. To do so, we estimate cross-country regressions of idiosyncratic consumption growth (countryspecific consumption growth adjusted for world consumption growth) on idiosyncratic income growth (Obstfeld, 1994; Lewis, 1995, 1996; Asdrubali, Sørensen, \& Yosha, 1996; Sørensen \& Yosha, 1998; Sørensen, Yosha, Wu \& Zhu, 2007; Kose, Prasad, \& Terroes, 2009). If consumption risk is shared, the estimated coefficient in this regression should be low, as idiosyncratic consumption growth of a country should be independent of idiosyncratic income growth. We estimate this cross-country regression for each year in our sample and analyze the time-series movements in the estimated coefficient. We find that consumption risk sharing was low during the World War periods as well as during Bretton Woods, when less than 20\% of idiosyncratic income shocks were diversified away. On the other hand, consumption risk sharing was high during the early part and the last part of our sample, as well in the interwar period before World War II. During these periods, around $50 \%$ of movements in idiosyncratic income growth were diversified away.

Having established that there is strong time-variation in the degree of international financial integration and consumption risk sharing, we investigate explicitly whether capital market integration leads risk sharing or vice versa. In order to test for this link, we run predictive regressions of future consumption risk sharing on current financial integration and vice versa. We find clear evidence that financial market integration leads consumption risk sharing, but we find no evidence that consumption risk sharing leads financial market integration. Moreover, we find that there is a time lag between movements in consumption risk sharing and market integration. Whereas the contemporaneous correlation between capital market integration and consumption risk sharing is statistically insignificant, there is significant predictability of risk sharing by market integration at horizons of five to ten years. In a nutshell, our results imply that it takes several years until higher integration is followed by higher risk sharing.

We also examine the question whether changes over time in consumption risk sharing 
might be related to changes in the level of trade integration and exchange rate flexibility. This part of our analysis is inspired by the finding in Kose, Prasad, Rogoff \& Wei (2009) that trade openness and financial integration both matter jointly for risk sharing of emerging markets and the insights of Cole \& Obstfeld (1991) that exchange rate flexibility can improve risk sharing via changes in the terms of trade. We find that changes in the level of exchange rate flexibility are unrelated to changes in risk sharing. On the other hand, we find some evidence that trade integration helps foster risk sharing. For instance, if we split up risk sharing into sharing of permanent shocks to output and sharing of transitory shocks to output (Artis \& Hoffmann, 2008), we find that trade integration helps smooth permanent shocks to output. Also, since trade integration and capital market integration have both been constantly increasing since the mid-1970s in particular, we find that trade and capital market integration have contributed jointly to the increase in consumption risk sharing that we have witnessed since the 1980s. We conclude that the relation between capital market integration and risk sharing is strong, and that there is some evidence that trade integration and risk sharing are related. We cannot find evidence that exchange rate flexibility has mattered much for risk sharing.

Moving from a situation with less than full consumption risk sharing to one with full risk sharing should lower consumption volatility due to the elimination of idiosyncratic shocks and, hence, should be welfare-increasing for risk averse investors. In order to quantify how important changes in consumption risk sharing are in economic terms, we calculate welfare gains from international consumption risk sharing. These calculations represent the "utility costs" of having less-than-perfectly integrated capital markets. We find that these utility costs line up with our measure of consumption risk sharing over time in the sense that low levels of risk sharing are also times with high utility costs. Moreover, we find utility costs to be quite substantial during times of low risk sharing which suggests that time-variation in consumption risk sharing has significant economic consequences and that understanding the drivers of risk sharing matters. 


\section{Related literature and our contributions in relation to this literature}

There is a sizeable literature relating capital market integration to volatility, comovement of economic activity, and risk sharing. For instance, Sørensen, Yosha, Wu \& Zhu (2007), Kose, Prasad, \& Terroes (2009), and Bai \& Zhang (2012) propose explanations for reconciling empirical findings of high capital mobility during the period since the break-down of the Bretton Woods and the less than perfect consumption risk sharing that characterizes this period as well. Bekaert, Harvey, Lundblad \& Siegel (2007) link capital market liberalization/integration during the last couple of decades in emerging markets to GDP changes. Kalemli-Ozcan, Papaioannou \& Peydro (2013) and Kalemli-Ozcan, Papaioannou \& Perri (2013) study recent banking and capital market integration and its effect on economic synchronicity. Some of these papers argue that capital market integration has had a sizeable effect on consumption volatility (Bekaert et al., 2007) and comovement of economic activity (Kalemi-Ozcan et al.) whereas other argue that risk sharing is still not as high as should be expected (Bai \& Zhang, 2012). Common to this literature is its use of data covering (parts of) the period since the break-down of the Bretton Woods. This period has been a period of generally increasing capital market integration and international capital flows. A key difference between these papers and our paper is that we use a much longer sample period. This allows us to study transitions between periods where capital market integration was increasing but also, importantly and generally different from the above-mentioned papers, periods where capital market integration was actually decreasing and study the link to market integration. In doing so, we verify that consumption risk sharing has gone up after the increase in capital market integration that has taken place during the periods since the early 1970s, but also that consumption risk sharing has gone down after periods with drops in capital market integration.

A related literature examines whether financial integration and liberalization promotes (e.g., Bekaert, Harvey \& Lundblad, 2005) economic growth by making financing opportunities more easily available to firms and households or reduces (e.g., Stiglitz, 2000) economic growth 
by making countries more exposed to sudden shifts in capital flows. ${ }^{2}$ We are indirectly related to this literature as we also examine the relation between capital market integration and economic activity. Our focus on risk sharing is different, though.

Our paper is structured as follows: In the next section, we describe the data we use. In Section 3, we study time variation in consumption risk sharing, and in Section 4 we study time variation in financial market integration. Section 5 relates the two and shows that financial market integration leads consumption risk sharing. In Section 6, we study the welfare implications of our findings. Section 7 provides some robustness checks, and a final section concludes.

\section{Data}

Our main source for long-term asset return is the DMS (Dimson, Marsh, Staunton) global returns data, kindly provided by Morningstar, which starts in 1900. We extend these returns with data from the GFD (Global Financial Data) database and Datastream. We work at an annual frequency and our combined sample covers the period from 1875 to 2012. The set of countries in our sample is: Australia, Belgium, Canada, Denmark, France, Germany, Italy, Japan, Netherlands, Norway, South Africa, Spain, Sweden, Switzerland, United Kingdom, and United States.

The asset return data are the total nominal returns to the equity markets of the specific countries. We also have T-bills and returns to long government bonds in our data set. Using T-bills we can calculate excess returns on stock and bonds. We use these additional fixed

\footnotetext{
${ }^{2}$ Kose, Prasad, Rogoff \& Wei (2009) conclude in their survey that "our critical reading of the recent empirical literature is that it lends some qualified support to the view that developing countries can benefit from financial globalization, but with many nuances,"and that "there is little systematic evidence to support widely cited claims that financial globalization by itself leads to deeper and more costly developing country growth crises."
} 
income return series to show that the results we derive using stock returns are robust. ${ }^{3}$

We use real consumption and real GDP data to measure the degree of consumption risk sharing. We obtain these data from the Barro and Ursua dataset, at http://rbarro.com/ data-sets/ and update it to 2012 with Datastream.

An important contribution of our paper is its use of long-term data. One advantage of a long dataset, as discussed in the Introduction, is that we get more episodes of increases and decreases in integration and risk sharing and consequently more power in our tests. On the other hand, one also needs to acknowledge that data extending back $140+$ years for many countries are not of the same high quality as, e.g., the Bretton Woods data that are normally used in the related literature. For instance, data for some years might be based on interpolations, and consumption data might be backed out from residuals, as described in the Barro and Ursua files. We can do some robustness checks on this issue, though. Based on the assumption that more recent data have higher quality, we run our main regressions over different subsamples of the full 1875-2012 sample. We run the regressions over a sample where we exclude the first 25 years, i.e. on a subsample from 1900-2012, and a sample where we exclude the first 70 years, i.e. on a post-WWII 1945-2012 subsample. We describe the results from these tests in more detail in Section 7, but already mention here that we find the same qualitative results as over the full sample period. We can also compare our postWWII data with the Penn World Tables (PWT) that start in 1960 (Feenstra et al., 2015). We calculate the correlation between our GDP growth and PWT GDP growth country by country, and likewise country-by-country correlations for consumption growth. We find that all country-by-country correlations between our GDP and PWT GDP growth rates are above 0.5, and eight out of the twelve correlations are above 0.8. For consumption, nine our of the twelve correlations are above 0.7. The average correlation across countries is 0.79 for GDP

\footnotetext{
${ }^{3}$ It would have been interesting to investigate price-earnings or price-dividend ratios across countries as it would have allowed for additional tests of integration, for instance using the approach of Beakert, Harvey, Lundblad \& Siegel (2013). However, such series are unfortunately not available for many countries for the sample period we study.
} 
growth and 0.65 for consumption growth. ${ }^{4}$ In the end, acknowledging that historical data are of a lower quality than modern-day data, it nevertheless seems that are our main conclusions are reasonably robust.

\subsection{Summary statistics}

In Table 1, we provide an overview of the times series we use. For most of the countries, we have consumption and GDP data going back to 1875 (for all countries except Australia, Belgium, and South Africa). For five countries (France, Germany, Spain, U.K., and U.S.), we have stock return data going back to 1875 , Australia starts in 1876, and for the remaining countries, the stock return sample starts in 1900.

The average annual growth rates of real consumption and GDP are around two percent, ranging from a low average consumption growth of $1.29 \%$ per year in Switzerland to a high of $2.47 \%$ in Japan (for GDP: low 1.28\% in South Africa and high $2.57 \%$ in Germany). The standard deviations of GDP and consumption are around 3\%-5\%. Looking at returns, the numbers are very different. Stock returns have yielded around 10\% per year on average from a low of $8.87 \%$ in Belgium to a high of $14.14 \%$ in Sweden. Returns are of course also much more volatile than real consumption or GDP growth rates with return volatilities being around $20 \%$.

In order to provide further insights into the basic characteristics of our data, we show the relative GDP weights (as a share of world GDP) of our sample countries over different subsamples in Table 2. The table shows how the economies of, in particular, France, Germany, and the UK have declined in relative size during our sample, whereas, in particular, Japan and the US have gained in relative size over the last 140 years.

\footnotetext{
${ }^{4}$ For four countries, the correlations between our consumption growth series and the PWT consumption growth series are below 0.5. Without these four countries, the average correlations are 0.75 . We checked our main results without those four countries. Results are robust.
} 


\section{Time-variation in consumption risk sharing}

The overall goal of our paper is to investigate how and if consumption risk sharing is influenced by financial integration, how consumption risk sharing varies through time, and some of the consequences of time-varying risk sharing. Consumption risk sharing means that idiosyncratic shocks to consumption are diversified away and thus shared with other countries. In the standard textbook setting with full financial integration, this implies that income growth of a country should be uncorrelated with consumption growth of the country.

Obstfeld (1994) pioneered the approach of measuring consumption risk sharing by regressing individual country consumption growth on world consumption growth or worldincome growth. Asdrubali, Sørensen, \& Yosha (1996), Sørensen \& Yosha (1998), Sørensen, Yosha, Wu \& Zhu (2007), and Kose, Prasad, \& Terroes (2009) extend the approach of Obstfeld, and show that the degree of consumption risk sharing can be estimated from a regression of deviations of own-country consumption growth $\left(\Delta c_{i, t}\right)$ from world consumption growth $\left(\overline{\Delta c_{t}}\right)$ on deviations of own-country income growth $\left(\Delta y_{i, t}\right)$ from world income growth $\left(\overline{\Delta y_{t}}\right)$ :

$$
\Delta c_{i, t}-\overline{\Delta c_{t}}=\alpha+\beta\left(\Delta y_{i, t}-\overline{\Delta y_{t}}\right)+\varepsilon_{i, t}
$$

We measure world growth (consumption and income) as GDP-weighted averages across countries, updating the GDP weights each year. A key point in Asdrubali, Sørensen, \& Yosha (1996) and Sørensen \& Yosha (1998) is that the $\beta$ from this regression can be interpreted as a measure of the degree of consumption risk sharing, as it quantifies the sensitivity of idiosyncratic consumption growth to changes in idiosyncratic income growth. A lower $\beta$ therefore implies that idiosyncratic domestic consumption moves less with changes in idiosyncratic income and implies a higher degree of consumption risk sharing. In particular, a $\beta$ of zero implies perfect consumption risk sharing, whereas a $\beta$ of one implies no consumption risk sharing at all.

We are interested in time variation in consumption risk sharing. In order to calculate a 
time-series with estimates of the degrees of consumption risk sharing, we proceed as follows: We estimate the above equation for each year in our sample, i.e. we conduct a cross-sectional regression of consumption growth (as deviation from world consumption growth) on income growth (as deviation from world income growth), using all countries in the sample with available data. From this we obtain an estimate of the slope coefficient $\beta$ for each year.

We plot the resulting time-series of estimates and use the transformation $100-100 \cdot \widehat{\beta}$ in Figure 1 so that higher levels imply more risk sharing. Moreover, to filter out noise and facilitate interpretation, we smooth the transformed estimates with a kernel regression. ${ }^{5}$ From Figure 1, we see that consumption risk sharing is increasing during the first 25-30 years of the sample, declines and reaches low values during the Bretton Woods, and finally increases again during the last decades of the sample period. In terms of magnitudes, the figure shows that consumption risk sharing was low during the very early part of our sample and during Bretton Woods when less than $20 \%$ of idiosyncratic income growth was shared internationally. On the other hand, risk sharing peaked around the turn of the previous century, around the start of the second world war, and during the last decades of our sample, when around $50 \%$ of movements in idiosyncratic income growth was diversified away.

Our sample covers more than 140 years, which is a long period of time. It includes several severe shocks, such as financial and economic crises and wars that in addition affected some countries more than others. It is relevant to investigate how robust our measures are to controlling for such time fixed effects. Similarly, countries differ persistently with respect to financial systems, where some systems are more bank oriented (e.g., continental Europe) and others more market oriented (e.g., the US). In this regard, it is relevant to control for country fixed effects. In Figure 2, we present results from estimations of Eq. (1) via successive panel regressions over rolling 15 -years windows. We plot the resulting time-series of estimated $\beta$ coefficients (shown as $100-100 \cdot \widehat{\beta}$ to facilitate easy comparison with Figure 1 ) from panel regressions where we include (i) time fixed effects only, (ii), country fixed effects only, and (iii) country and time fixed effects. Even when we miss the first 15 years of data compared to

\footnotetext{
${ }^{5}$ We plot an unsmoothed version in the upper panel of Figure A.1 in the Internet Appendix.
} 
the procedure used to generate Figure 1, we conclude that the overall pattern of consumption risk sharing seems reasonable robust to using these different fixed effects specifications: risk sharing is increasing during the first years of the sample, declines during the interwar years, declines during Bretton Woods, and increases during the last decades of the sample.

\section{Time-variation in international financial integration}

We next turn to the question of how capital market integration varies over our sample period. We use the level of comovement of returns across countries as our measure of market integration. This is a standard measure often used in the literature (Longin \& Solnik, 1995; Quinn \& Voth, 2008), the idea being that markets behave more similarly when being integrated. We calculate it as follows. For each year in our sample period, we compute the cross-country dispersion of stock returns, $\operatorname{Disp}_{t+1}=\operatorname{var}\left(R_{t+1}\right)^{0.5}$, where $R_{t+1}$ is a vector of stock returns for all countries with available data. According to this measure, markets are more integrated during periods in time where the dispersion in returns across countries is low. The measure is model-free in the sense that it does not rely on an asset-pricing model or explicit exposures to common factors. In Section 7, we present results for two other measures of market integration: one based on an asset-pricing model(world CAPM) and one purely statistical based on exposure to common factors. Our results are robust to these alternative measures. Finally, we note that Quinn \& Voth (2008) show that return correlations are associated with de jure capital account openness providing a further argument for this measure of market integration.

\subsection{Results}

Figure 3 plots the time-series behavior of financial integration. As above for the risk sharing estimates, we invert the measure so that higher readings indicate more integration and we 
smooth the time-series via kernel regressions for ease of interpretation of the figure. ${ }^{6}$ We show results for integration measures based on the subgroup of countries for which we have stock return data throughout the full sample period (France, Germany, Spain, U.K., and U.S.), i.e. since 1875, and based upon the full group of countries since 1900.

The main thing to notice from the graph is that it provides an overall intuitive picture: Financial integration was very high during the period from 1875 until the beginning of the first World War, after which financial integration strongly declines. ${ }^{7}$ Financial integration stayed low between the two World Wars and during the Bretton Woods regime. Given the capital controls that characterized the Bretton Woods regime, it makes intuitive sense that financial integration was low during this period. Finally, we see that financial integration has improved dramatically after the end of the Bretton Woods in the beginning of the 1970s, as has also been reported elsewhere in the literature (e.g., Lane \& Milesi-Ferretti, 2007). During the last 10-15 years, the countries we look at here have been more highly integrated financially. The overall picture painted by Figure 3 is thus that financial integration was high before World War I, stayed low until the 1970s, after which it increased rapidly. Today, financial integration is estimated to be very high (relative to estimates for earlier periods).

Comparing Figures 1 and 3, we find that periods of high financial integration tend to be related to periods of high consumption risk sharing. In particular, levels of capital market integration and consumption risk sharing were both high during the first decades of the 20th century, low during Bretton Woods, and increasing and high after Bretton Woods. However, the turning points in the levels of integration and consumption risk sharing seem to be slightly different: Financial integration started to drop after WWI and kept on falling until WWII, whereas consumption risk sharing started to fall around WWII. Likewise, financial market integration started to increase around the late 1970s whereas consumption risk sharing started

\footnotetext{
${ }^{6}$ Moreover, we also plot an unsmoothed version of the cross-sectional dispersion measure in the lower panel of Figure A.1 for comprarison.

${ }^{7}$ We note that integration started decreasing shortly after 1900 both if we look at the full sample of countries, and the five countries for which we have data since 1875. In other words, it is not the mere inclusion of additional countries into our sample in 1900 that causes integration to drop after 1900, as we also find this in the dataset including only France, Germany, Spain, U.K., and U.S.
} 
to increase around the mid-1980s. In other words, eyeballing these smoothed time series of integration and risk sharing, it seems that capital market integration and consumption risk sharing are related, with integration leading risk sharing. In the next section, we provide direct tests of such relations.

\section{Does financial integration lead consumption risk sharing?}

In this section, we test whether financial integration leads consumption risk sharing. The motivation is simple and based on standard textbook models: If financial markets are not integrated, consumption risk sharing is hampered by the fact that agents cannot eliminate idiosyncratic consumption shocks via trade in financial assets. Hence, financial market integration should facilitate consumption risk sharing and we test for this hypothesis in the data. In addition, we expect that it may take some time for consumption risk sharing to increase after a rise in financial market integration, i.e. that the real side of the economy reacts with a lag to a change in the financial sphere of the economy. This seems plausible as agents need to learn about, and adjust to, such a change.

\subsection{Contemporaneous relations between integration and risk sharing}

As a first step towards understanding the link between capital market integration and consumption risk sharing, we look at the contemporaneous correlation of these two quantities. We calculate contemporaneous correlations between integration and risk sharing for overlapping windows of 1 year, 2 years, ...., 25 years. For correlations based on 2-year windows, we calculate the correlation between the average levels of integration over two years and average levels risk sharing over two years; for three-years windows, we calculate the correlation between the average levels of integration over three years and average levels of risk sharing over three years, etc. We plot the correlations in Figure 4 together with $95 \%$ con- 
fidence intervals around the estimated correlations. ${ }^{8}$ The main take-away from the figure is that the correlation is generally positive but that none of the correlations are significantly different from zero. Hence, even if the point estimates of the correlations intuitively build up with the horizons over which the correlations are measured, there seems to be no strong contemporaneous relation between risk sharing and integration, regardless of the length of the window used to compute the correlations. Hence, risk sharing and market integration are positively correlated as expected but the contemporaneous link seems rather weak and is not significantly different from zero.

\subsection{Predictive regressions}

Given our findings of a positive but insignificant positive correlation, we turn to an analysis of potential lead-lag relations next. More formally, we run predictive regressions of future measures of consumption risk sharing on current measures of financial market integration:

$$
\overline{\text { Risk sharing }}_{t+h}=\alpha_{h}+\gamma_{h} \overline{\text { Market integration }}_{t+1-k}+\varepsilon_{t+h} \text {. }
$$

As the dependent variable, we use the average of our consumption risk measure from Eq. (1) over the following $h$ years, with $h$ being one, two, five, or ten years. We have overlapping observations when $h>0$, so we use Newey-West (1987) and Hodrick (1992) standard errors when we calculate $t$-statistics. Ang \& Bekaert (2007) find that the Hodrick (1992) standard errors are well suited and reliable for predictive regressions with overlapping observations such as the ones we present in this section. We regress the $h$-period average of our risk sharing measure on the $k$-period (over $k$ equal to one, two, five, and ten years) lagged average of our integration measure.

In order to gauge the direction of impact, we also run the reverse regression, i.e.:

$$
\overline{\text { Market integration }}_{t+h}=\alpha_{h}+\gamma_{h} \overline{\text { Risk sharing }}_{t+1-k}+\varepsilon_{t+h} \text {. }
$$

\footnotetext{
${ }^{8}$ The confidence intervals are based on a moving-block bootstrap with 10,000 repetitions.
} 
We standardize the times series of integration and risk sharing in both regressions to facilitate ease of interpretation. Moreover, it is important to note that we do not use the kernel smoothed estimates of our risk sharing and market integration measures shown in Figures 1 and 3 in these regressions but the unsmoothed estimates (shown as dashed lines in Figure A.1 in the Internet Appendix). The kernel smoothed series in Figures 1 and 3 are smoothed based on knowledge of the full sample and thus cannot be used in these predictive regressions. ${ }^{9}$ We employ the raw estimates $(h=1, k=1)$, or simple moving averages of these estimates $(h>1, k>1)$, instead so that we are only using information up to time $t$ for forecasting risk sharing or integration over future periods $t+h$. Moreover, these estimates are not as persistent as Figures 1 and 3 might suggest (the first-order autocorrelations of the unsmoothed series are $20.5 \%$ for risk sharing and $34.7 \%$ for market integration) which is relevant for interpreting the results from predictive regressions.

Results are clear-cut and reported in Table 3. Risk sharing is predictable by market integration, but there is no evidence that market integration is predictable by risk sharing. In other words, after a rise in capital market integration we also see more consumption risk sharing in the future, presumably because market integration facilitates risk sharing. This is a central message of our paper.

Looking at the results in Table 3, we also find that it generally takes time before risk sharing increases after markets become more integrated. For instance, if simply regressing next year's risk sharing on this year's level of integration, the relationship is insignificant with a Newey-West $t$-statistic of 1.43 and an $R^{2}$ of two percent. If instead relating the average level of risk sharing over the following ten years to this year's level of integration, we see a significant relation (NW $t$-statistic equal to 2.65) and an $R^{2}$ around ten percent. We also notice that the sign is "right", i.e. a higher level of financial market integration is followed by a higher level of consumption risk sharing. Finally, the economic magnitude seems large as a one standard deviation increase in integration leads to a 1.36 standard deviation increase in risk sharing over the next ten years.

\footnotetext{
${ }^{9}$ We smooth the estimates in Figures 1 and 3 simply for making the overall pattern more easily visible.
} 
Our measure of financial market integration is clearly volatile, as it is based on annual stock returns which are more more volatile than macroeconomic quantities such as consumoption growth (as also seen by the summary statistics in Table 1). For this reason, we see an even clearer relation between financial integration and consumption risk sharing when we smooth our measure of integration by using averages over the past one, two, five, or ten years. Indeed, the average of the last ten years of financial integration predicts next year's level of risk sharing, with a NW $t$-statistic of 2.96 and an $R^{2}$ of seven percent. Finally, we see that the level of integration during the last decade strongly predicts the level of risk sharing during this decade with an $R^{2}$ of $24 \%$. As above, we find sizeable economic effects with coefficients ranging from $0.13(k=2, h=1)$ to $2.08(k=10, h=10)$.

It seems important to stress that no matter whether we measure integration or risk sharing over one or several years, we do not find a significant relation between consumption risk sharing and future levels of financial integration, as shown by the results in the right panel of Table 3. Hence, we conclude that integration is followed by risk sharing but not the other way around.

\subsection{Non-overlapping observations}

As just discussed, Table 3 documents a relation between lagged levels of integration and current levels of risk sharing. Even when we use Hodrick (1992) standard errors that are designed for situations as the ones we present above, in that they that address the issue of overlapping observations, one nevertheless might still be concerned that the presence of overlapping observations in Table 3 could influence the results we find. In order to make a perspective on this, we present in Figure 5 a scatter plot of the change in equity market integration over one decade and the change in consumption risk sharing over the next decade. Hence, each dot in the figure represents a combination of a non-overlapping change in integration and subsequent change in risk sharing. The span of our sample period allows us to calculate 14 such combinations. The figure reveals a positive relation, with a correlation of 
0.57. This implies that increases (decreases) in capital market integration have been followed by increases (decreases) in risk sharing.

\subsection{Trade openness, exchange rate flexibility, and consumption risk sharing}

We have shown that capital market integration leads consumption risk sharing. Over the long sample period used in this paper, equity market integration was not been only thing that changed. Hence, one might wonder whether other factors have influenced risk sharing in addition to the influence of changes in capital market integration. In this section, we investigate two channels that have been high-lighted in the literature: trade openness and exchange rate flexibility.

Trade openness. Prasad, Rogoff \& Wei (2009) argue that trade openness and financial integration both matter jointly for risk sharing, and verify this for emerging markets throughout the last couple of decades. Our sample is based on developed markets over a long sample period, but it still seems interesting to investigate whether including trade openness (as a measure of integration in the real economy) has helped foster risk sharing.

To do so, we compute trade openness as the sum of exports and imports relative to GDP for all 16 countries in our sample. The data on imports and exports are from the GFD and start in 1900. We use GDP weights to calculate an overall measure of trade openness. The upper panel of Figure 6 shows a plot of the log of this measure. As can be seen, there has been a strong upward trend in trade openness since WWII. Trade openness is also very persistent. Compared to our measures of risk sharing and market integration (which have first-order autocorrelations of $20-35 \%$ as noted above), the trade openness time series has an autocorrelation of $99 \%$ and is clearly non-stationary, even over this long sample period. Hence, in the following we work with first differences of trade openness. 
Exchange rate flexibility. Cole \& Obstfeld (1991) highlighted the potential important influence of relative price movements for risk sharing. Cole \& Obstfeld (1991) showed that changes in terms of trade could pool national output risks and thereby provide risk sharing through other channels than market or trade integration. ${ }^{10}$

We capture movements in relative prices via movements in exchange rates (we do not have data for terms of trade). We compute the cross-sectional volatility of exchange rate changes. This is similar to our integration measure for equities based on cross-sectional dispersion and has a similar interpretation. The lower panel of Figure 6 shows the time series movements in exchange rate volatility (along with averages for different subsamples as horizontal lines). We see that there was very little exchange rate variability during the Gold Standard before WWI, exchange rate variability between WWI and WWI, low exchange rate variability during Bretton Woods, and more exchange rate variability after the breakdown of Bretton Woods. Hence, this measure captures intuitive differences in exchange rate volatilities during periods of floating and fixed exchange rates.

To investigate whether trade openness and exchange rate flexibility matter for risk sharing, we run the following regression:

$\overline{\text { Risk sharing }}_{t+h}=\alpha_{h}+\tau_{h} \overline{\Delta \text { Trade openness }}_{t+1-k}+\kappa_{h}{\overline{\Delta \mathrm{FX}^{\perp}}}_{t+1-k}+\gamma_{h}{\overline{\text { Market integration }^{\perp}}}_{t+1-k}+\varepsilon_{t+h}$

where $\Delta \mathrm{FX}$ is exchange rate volatility. This is similar to the regression underlying Table 3 but additionally includes changes in trade openness, orthogonalized exchange rate volatility, and orthogonalized market integration. In our orthogonalization, we want to give trade openness and exchange rate flexibility maximum influence in order to be conservative. We therefore orthogonalize as follows: We first regress $\Delta \mathrm{FX}$ volatility on $\Delta$ Trade openness and save the residual. We then regress capital market integration on $\Delta$ Trade openness and the $\Delta$ FX residual and save the new residual. This implies that we use trade openness itself,

\footnotetext{
${ }^{10}$ Cole \& Obstfeld (1991), p. 5, wrote: “..... for certain parameter choices terms-of-trade responses alone provide perfect insurance against output shocks. In such cases the gains from international portfolio diversification (and possibly the gains from intertemporal foreign trade as well) are nil.".
} 
the part of FX volatility that is uncorrelated with trade openness, and the part of market integration that is uncorrelated with trade openness and FX volatility.

We again investigate several forecast horizons $(h)$ and form (moving) averages of our predictors over the previous $k$ years to capture lower frequency movements in integration and risk sharing. Table 4 reports the results. The table shows that market integration seems to be more important for risk sharing than trade integration and exchange rate flexibility. This is clearly apparent when looking at the results for $k=10$ where market integration is strongly significant for any forecast horizon whereas trade integration and FX flexibility are only significant for long forecast horizons, and trade openness even has a counterintuitive sign (higher levels of trade integration implying lower levels of risk sharing). For lower levels of $k$, market integration is significant for longer forecast horizons, but not for shorter horizons, trade integration has the "wrong" sign when significant, and FX flexibility is not significant at all for $k=5$ or 10 . These results imply that risk sharing is positively influenced by lagged financial integration, but not much by real integration (trade integration) or exchange rate flexibility. This result seems quite interesting due to the fact that we use that part of market integration that is uncorrelated with trade openness and exchange rate flexibility.

Figures 1, 3 and 6 show that trade openness, capital market integration, exchange rate flexibility, and risk sharing all start increasing significantly after the mid-1970s. Hence, it seems likely that results for the post-Bretton Woods period might differ from results based on the total sample period. Table 5 shows results for the 1974-2012 sample. We see that trade integration plays a more important role for risk sharing during this period, and an even more important role than market integration when forecasting over shorter horizons. When forecasting risk sharing over longer horizons, market integration still plays a role, whereas FX flexibility generally does not (FX volatility is sometimes significant when using Newey-West t-statistics but not when using Hodrick statistics).

We conclude from the tests in Tables 4 and 5 that market integration is closely related to future risk sharing and more so than trade integration and exchange rate flexibility. For the period after 1974, market integration and trade integration are both related to the increase 
in consumption risk sharing we have seen. Exchange rate flexibility seems to be unrelated to changes in risk sharing.

\subsubsection{Permanent and transitory shocks}

Artis \& Hoffmann (2008) show that the volatility of short-term (business cycle) shocks to output has decreased by more than the volatility of permanent shocks to output during the 1980-2000 period. Based on the permanent income hypothesis, they show that consumption theoretically should react more to permanent shocks, and document empirically that consumption risk sharing has increased more than commonly perceived in the literature during the 1980-2000 period. They find that financial integration has fostered this increase in risk sharing. We follow Artis \& Hoffmann (2008) and decompose GDP country by country into a transitory and a permanent component. ${ }^{11}$ Then we calculate our measure of risk sharing, based on Eq. (1), using, respectively, the transitory part of GDP and the permanent part of GDP as the right-hand side variable. Finally, we run our predictive regressions of risk sharing on market integration using, respectively, risk sharing of transitory shocks and risk sharing of permanent shocks as the dependent variables. We show the results for these regressions in Tables 6 and 7. We find that market integration is positively related to risk sharing of both transitory and permanent shocks on the long horizon. Additionally, we find that trade integration is important for the sharing of permanent shocks, but not of transitory shocks. This indicates that part of the reason why trade integration does not seem to matter much in Table 4 is that shocks to both the transitory and permanent component of GDP are considered jointly in these regressions; if separating out permanent shocks, as in Tables 6 and 7,the role of trade integration for risk sharing becomes clearer.

\footnotetext{
${ }^{11}$ We refer to Artis \& Hoffmann (2008) for details on the construction of the permanent and transitory components to conserve space.
} 


\subsubsection{Panel-regression results for importance of trade integration, exchange rate flexibility, and financial crises}

We have country-by-country measures of trade integration and exchange rate flexibility. We follow Sørensen et al. (2007) and run panel regressions of consumption growth in a given country on GDP growth in the same country like in Section 3, but we now include additional regressors to control for trade integration and exchange rate flexibility. Moreover, we interact GDP growth with trade integration and exchange rate flexibility, respectively. This panel regression provides us with further evidence on how risk sharing has evolved over time and has the additional advantage that it does not use overlapping observations and is more directly related to procedures otherwise used in the literature by, e.g., Sørensen et al. (2007).

We show the results from this regression in Table 8. The panel regressions include both country and time fixed effects and we employ two-way clustered standard errors (clustered by country and year). We find an unconditional average degree of risk sharing across all countries and all time periods of $0.39(1-0.61$, see Table 8$)$. We also find that risk sharing is higher during periods where trade integration is higher; a negative slope on the interaction term $\Delta G D P_{t} \times \Delta$ Trade $_{t-1}$ means that more trade openness lowers the coefficient on $\Delta G D P_{t}$, which in turn implies that own-country GDP growth matters less for own-country consumption growth. Hence, we find higher risk sharing during periods of higher trade integration. Finally, we find no relation between exchange rate flexibility and risk sharing in these regressions.

The role of financial crises. Using a similar panel regression set-up, we can investigate whether risk sharing varies over time with the severity of financial crises. Reinhart \& Rogoff (2009) identify episodes of local crises, meaning the occurrence of currency, inflation, debt (external or internal), banking, or other crises in a country. Their variable ranges from 0 (no crisis) to 6 (all of these crises occur simultaneously in a country) for every country and every year. We include this variable in our panel regression and interact it with GDP growth. We also include a global crisis indicator, calculated as the GDP-weighted average of 
country-specific crisis indicators, and its interaction with GDP growth. The results from this regression are in Table 9. We find that the interaction terms with global crises is significant, implying that risk sharing is time-varying and higher during periods of global crises. The overall level of risk sharing does not depend on local crises.

Our finding that risk sharing is counter-cyclical, i.e. higher during crisis, differs from findings in, e.g., Hoffmann and Sherbakova-Stewen (2011) and Storesletten et al. (2004) who find risk sharing to be lower during economic downturns. There are a couple of possible explanations. First, we look at international data and global crises whereas other authors often look at domestic crises (Storesletten et al., 2004 investigate U.S. micro data and Hoffmann and Sherbakova-Stewen, 2011 investigate U.S. states). Second, given our findings in Section 5.4.1, the result might simply reflect that there is little idiosyncratic risk to share during crises, implying that risk sharing appears high. One explanation could be that the fraction of GDP variance that is insurable declines, making risk sharing appear higher in the regressions than it actually is.

\section{Consequences of time-varying consumption risk sharing}

So far, we have demonstrated that there is a considerable degree of time-variation in international consumption risk sharing and that risk sharing depends on lagged capital market integration. One implication of time-varying risk sharing is that the costs of imperfect insurance against consumption fluctuations will also vary through time (Lucas, 1985). We analyze this in this section and quantify the consequences of imperfect risk sharing.

Perfect risk sharing means eliminating idiosyncratic shocks to consumption. All else equal, imperfect risk sharing thus implies higher variance of consumption growth which lowers utility of a risk-averse consumer compared to a situation of perfect risk sharing. In this section, we illustrate the benefits (in welfare terms) of international risk sharing, and, in particular, the time-variation in these welfare gains. 
We measure the welfare gain from international risk sharing based on the following reasoning: If risks are perfectly shared (and preferences are the same, etc.), consumption growth rates of different countries should move in lockstep. The consumption uncertainty consumers face in this situation is the risk of fluctuations in world consumption, i.e. the variance of world consumption. On the other hand, when there is no risk sharing, consumption growth will be more driven by GDP growth in individual countries. The risk the consumer in each country faces in this situation is the volatility of individual consumption growth. The difference between the volatility of world consumption and the average of volatilities of individual countries' consumption is the gain from consumption risk sharing.

We follow Lucas $(1985,2003)$ and assume that consumers have CRRA preferences over consumption

$$
U_{t}=\frac{\left(1+C_{t}\right)^{1-\theta}}{1-\theta}
$$

where $C_{t}$ is annual consumption and $\theta$ is the coefficient of relative risk aversion. We calculate the welfare gain from switching to perfect consumption risk sharing as the difference in utilities between consuming world consumption and consuming actual levels of consumption in the individual countries. Specifically, the two levels of utility are calculated as (i) the utility from consuming world consumption which is the GDP-weighted average of consumption in the individual countries (call this level of utility $\left.U\left(C^{\text {perfectly shared }}\right)\right)$ and (ii) the utilities from consuming own-country consumption. These own-country consumption utilities are then combined using GDP-weights (call this level of utility $\left.U\left(C^{\text {non-perfectly shared }}\right)\right)$. The resulting gain in utility is calculated as:

$$
\left.\left.\frac{1}{T} \sum_{t=1}^{T} U\left(C^{\text {non-perfectly shared }}\right)\right)-\frac{1}{T} \sum_{t=1}^{T} U\left(C^{\text {perfectly shared }}\right)\right)
$$

We use 10 years to calculate the average utilities, and we let the calculations roll through the sample. We note that average utility takes risk into account due to the concavity of the utility function.

We plot the (log) difference in utilities in Figure 7 using two different values for the 
risk aversion parameter; $\theta=4$ and $\theta=10$. We find that there are large swings in welfare costs. For example, the spike of $-6.5 \%$ in 1955 (for $\theta=10$ ) means the representative consumer would have been willing to give up $6.5 \%$ of consumption to eliminate idiosyncratic consumption volatility in 1955. Figure 7 shows that there is time-variation in the amount of consumption the consumer in the non-integrated world is willing to give up in order to avoid idiosyncratic consumption fluctuations.

In particular, the utility cost of imperfect risk sharing is very large around WWII, and has been declining more or less continuously since then in line with increased market integration and risk sharing over the same time period. Throughout the last couple of decades, the difference is very small indicating that there is no big difference in the amount of consumption that consumers are willing to give up compared to what consumers in a world of perfect risk sharing would give up. In other words, consumption risk sharing today is so high that further improvements will not lead to large welfare gains anymore (as judged by our metric).

We can also comment on the economic magnitudes of the effects. During the first half of our sample period, for example, the difference between the two certainty-equivalents in Figure 7 is approximately $-1.10 \%$ for $\theta=4$ and $-1.99 \%$ for $\theta=10$. In the second half of our sample, these numbers increase to $-1.03 \%$ and $-1.60 \%$ respectively, and for a very recent sample from 1991 - 2012, these numbers are almost zero at $-0.30 \%(\theta=4)$ and $-0.49 \%$ $(\theta=10)$. Hence, higher integration has brought considerable welfare gains and it thus seems relevant to understand which factors drive risk sharing. Looking at the time-variation in Figure 7 , the time-series fluctuations in utility losses seem to line up reasonably well with fluctuations over time in consumption risk sharing, as documented in earlier parts of the paper. Hence, the degree of consumption risk sharing has significant welfare implications and periods of time with low risk sharing are also times with significant welfare costs. This underscores the main theme of this paper: consumption risk sharing matters and it seems important to understand the drivers of consumption risk sharing. As shown above, market integration seems to be one driver of risk sharing. 


\section{Additional results and robustness}

In this section, we present additional results and run some robustness checks on earlier results. We provide further robustness results in the Internet Appendix to our paper.

A CAPM measure of integration and sub-samples. We calculated a second measure of market integration based on a world-CAPM, i.e. a model where assets are priced according to their exposures to the world market portfolio. We are interested in the dispersion of the idiosyncratic part of countries' returns, the point being that the more integrated countries are, the lower is the cross-country dispersion of idiosyncratic risk. To find the cross-country dispersion of idiosyncratic risk, we proceed as follows. We estimate a world-CAPM time-series regression (over the full sample period) for each of the 16 countries, i.e. we regress the return of a country on the return on the world-market portfolio. We save the residual time-series for each country and take the absolute values. We then have 16 time-series of absolute residuals. For each year, we take the GDP-weighted cross-country average of idiosyncratic volatilities, so that we have one time-series from 1875 to 2012 of "average idiosyncratic volatility". Panel (a) of Figure A.2 shows a time-series plot of this measure.

We then run the same predictive regressions as in Table 3 but using the CAPM-based measure of integration. We report results in Table A.I in the Internet Appendix and find that the basic result from above is unaffected: There is strong statistical evidence that integration leads risk sharing; perhaps not when we set $k=1$ and $h=1$, but when we smooth out fluctuations in the level of integration, by using its average over several years and predict future risk sharing, or if we predict the average of the next several years of risk sharing. And, as above, there is no effect from risk sharing to future integration. Hence, our predictability results are robust towards using a model-free measure of financial integration, as in Table 3, or a CAPM-measure, as in Table A.I .

We find a high level of financial integration in the early part of our sample period (see 
Figure 3). During this part of our sample, we only have data for few countries (France, Germany, Spain, U.K., and U.S.), though. In order to judge whether our result that financial integration leads risk sharing is driven by these early years with few countries, we present in Table A.II results from two subsample regressions: one for the 1900-2012 period and one for the 1946-2012 period. Table A.II reveals that our results do not depend on the early periods, as we find that financial integration leads consumption risk sharing also when excluding early subsamples. For instance, if focusing on the 1946-2012 period, we find that the average degree of financial integration during a decade significantly predicts the average degree of consumption risk sharing during the following decade with an $R^{2}$ of twenty percent.

A common-factors measure of market integration. So far, we have presented results using two measures of financial integration. Pukthuanthong \& Roll (2009) advocate a third measure, and we checked our results using that measure. Pukthuanthong \& Roll (2009) suggest to measure financial integration by the proportion of a country's returns that can be explained by common, global factors. We have annual data (Pukthuanthong \& Roll, 2009 use daily data), so we proceed as follows. We use rolling windows of 25 years to compute the covariance matrix $C V_{t-24 ; t}$ of stock returns for a given 25-year window. Next, we factorize the covariance matrix $C V_{t-24 ; t}=\Phi_{t-24 ; t} \Lambda_{t-24 ; t} \Phi_{t-24 ; t}^{\prime}$ of stock returns and select the number of factors based on the largest eigenvalues and such that the common factors account for at least $80 \%$ of return (co-) variances. This usually requires two or three factors. Finally, we form common factor portfolios $\Phi_{t-24 ; t} R_{t-24 ; t}^{\prime}$ based on the eigenvectors $\left(\Phi_{t-25 ; t}\right)$ of the covariance decomposition. We then regress the stock returns of individual countries on these common factor returns and compute the $R^{2}$ for each country. We take the average of these $R^{2} \mathrm{~s}$ to find the overall measure of integration at each point in time. We call this measure the "Importance of common factors" and plot it in Panel (b) of Figure A.2 in the Internet Appendix. Using this measure of integration, we find that financial integration has increased sharply since the breakdown of the Bretton Woods, and reach historically high levels during the last years of our sample. We also find that the degree of financial integration declined after WWI and stayed low until the mid-1960s (when using all countries) or the mid-1970s 
(when using France, Germany, Spain, U.K., and U.S.). Hence, we conclude that even if the message provided by Figure A.2 is perhaps not as clear as the message provided by Figure 3 - due to the rolling window of estimation - the conclusions regarding periods of financial integration is to a large extent robust in qualitative terms. ${ }^{12}$

Additional robustness on predictive regressions. Next, we also look at measures of financial integration based on excess returns (stock returns minus the risk-free rate) and government bonds and T-bills instead of using simple stock returns to measure financial integration. We report these regressions in the Internet Appendix in Tables A.III and A.IV, respectively, and find that they corroborate our earlier results: Market integration over the past decade positively forecasts consumption in the future, but not the other way around. Our results, thus, are not sensitive to the kinds of returns we use to measure financial integration.

We also run an additional robustness check related to the predictive regression results and add a lag of the dependent variables. We do so because using larger values of $k$ (the period over which we measure consumption risk sharing) leads to an increasingly persistent dependent variable by construction. Hence, this is an additional check on the influence of persistent variables on our results (additional to the different sets of standard errors that we in the tables above use to deal with this persistence). Table A.V in the Internet Appendix reports results for this exercise and we again find that our results are robust in the sense that equity market integration leads risk sharing.

Asymmetric effects. We also investigated whether there are asymmetric effects in the relation between integration and risk sharing, i.e. whether risk sharing mainly changes when integration goes, e.g., up (or down). We have investigated this in different ways, for instance, interacting our integration measure with a dummy being equal to 1 if integration increases. The overall conclusion from these tests is that there are no significant asymmetric effects. This means that risk sharing responds to changes in integration, both when integration goes

\footnotetext{
${ }^{12} \mathrm{We}$ do not run predictive regressions of risk sharing on this measure of integration as this measure is based on rolling windows of 25 years so that we would confound the forecast horizon and estimation window.
} 
up and down, and there are no differences depending on whether integration increases or decreases.

Obstfeld (1994) measure of risk sharing. We use the measure of consumption risk sharing developed and used by Asdrubali, Sørensen, \& Yosha (1996), Sørensen \& Yosha (1998), Sørensen, Wu, Yosha \& Zhu (2007), and Kose, Prasad, \& Terroes (2009). There is an alternative, closely related measure used in Obstfeld (1994) and Lewis (1999), where consumption risk sharing is measured via a regression of own-country consumption growth on own-country income growth $\Delta c_{i, t}=\alpha+\beta \Delta y_{i, t}+\varepsilon_{i, t}$ instead of using deviations from world growth. As a robustness test, we also used this measure and find results very similar to those reported here. This finding makes sense as we are using cross-sectional regressions and the $\alpha$ in this regressions ensures that all variables are cross-sectionally demeaned. This is similar to using our measure in the main text that subtracts GDP-weighted global growth rates.

All in all, over the last 140 years, we find strong and robust evidence that financial market integration has led to higher degrees of consumption risk sharing after a couple of years.

\section{Conclusion}

We investigate time-variation in capital market integration and consumption risk sharing over a period of almost 140 years, from 1875 through 2012. We first document considerable variation over time in consumption risk sharing and financial integration in stock markets. We find periods of very high risk sharing and integration, such as in the beginning of the sample period and at the very end of the sample period, and periods of low risk sharing and integration, such as periods surrounding WWII and during the Bretton Woods period. By exploiting variation over time, we document that there indeed is a clear-cut relation between capital market integration and risk sharing in the sense that higher financial market integration forecasts higher risk sharing in the future, whereas there is no effect the other 
way around. Hence, financial markets do indeed seem to deliver on one of their most basic functions, namely propagating risk sharing among agents. Finally, we calculate variation over time in the costs of having less than fully integrated capital markets. We find substantial fluctuations in these utility costs, with the periods surrounding WWII generating a high cost of up to five percent of utility, and at other times, such as in recent years, very low costs. 


\section{References}

[1] Ang, Andrew, Geert Bekaert, 2007. Stock Return Predictability: Is it there? Review of Financial Studies 20, 651-707.

[2] Artis, Michael J., Mathias Hoffmann, 2008. Financial Globalization, International Business Cycles and Consumption Risk Sharing. Scandinavian Journal of Economics 110, $447-471$.

[3] Asdrubali, Pierfederico, Sørensen, Bent E., Yosha, Oved, 1996. Channels of interstate risk sharing: United States 1963-90. Quarterly Journal of Economics 111, 1081-1110.

[4] Bai, Yan, Zhang, Jing, 2012. Financial integration and international risk sharing. Journal of International Economics 86, 17-32.

[5] Barro, Robert J. and José F. Ursúa, 2008. Macroeconomic crisis since 1870. Brookings Papers on Economic Activity Spring 2008, 255-335.

[6] Bekaert, Geert, Harvey, Campbell, Lundblad, Christian, 2005. Does financial liberalization spur economic growth. Journal of Financial Economics 77, 3-55.

[7] Bekaert, Geert, Harvey, Campbell, Lundblad, Christian, Siegel, Stephan, 2007. Global growth opportunities and market integration. Journal of Finance 62, 1081-1137.

[8] Bekaert, Geert, Harvey, Campbell, Lundblad, Christian, Siegel, Stephan, 2013. The European Union, the Euro, and Equity Market Integration. Journal of Financial Economics 109, 583-603.

[9] Cole, H. L., and Maurice Obstfeld, 1991. Commodity Trade and International Risk Sharing: How Much Do Financial Markets Matter? Journal of Monetary Economics 28, 3-24.

[10] Feenstra, Robert C., Robert Inklaar, and Marcel P. Timmer, 2015. The Next Generation of the Penn World Table. Forthcoming American Economic Review.

[11] Hodrick, Robert, 1992. Dividend Yields and Expected Stock Returns: Alternative Procedures for Inference and Measurement. Review of Financial Studies 5, 357-386.

[12] Hoffmann, Mathias, Iryna Shcherbakova-Stewen, 2011. Consumption Risk Sharing over the Business Cycle: The Role of Small Firms' Access to Credit Markets. Review of Economics and Statistics 93, 1403-1416. 
[13] Kalemli-Ozcan, Sebnem, Elias Papaioannou, Fabrizio Perri, 2013. Global Banks and Crisis Transmission. Journal of International Economics 89, 495-510.

[14] Kalemli-Ozcan, Sebnem, Elias Papaioannou, Jose-Luis Peydro, 2013. Financial Regulation, Financial Globalization, and the Synchronization of Economic Activity. Journal of Finance 68, 1179-228.

[15] Kose, M. Ayhan, Prasad, Eswar, Rogoff, Kenneth, Wei, Shang-Jin, 2009. Financial Globalization: A Reappraisal. IMF Staff Papers, 8-62.

[16] Kose, M. Ayhan, Prasad, Eswar, Terroes, Marco, 2009. Does financial globalization promote risk sharing? Journal of Development Economics 2009, 258-270.

[17] Lane, Philip R., Milesi-Ferretti, Gian Maria, 2007. The external wealth of nations mark II: Revised and extended estimates of foreign assets and liabilities, 1970-2004. Journal of International Economics 73, 223-250.

[18] Lewis, Karen K., 1995. Puzzles in International Financial Markets. In: G. Grossman and K. Rogoff (Eds.), Handbook of International Economics. North Holland: Amsterdam.

[19] Lewis, Karen K., 1996. What can explain the apparent lack of international consumption risksharing? Journal of Political Economy 104 (2), 267-297.

[20] Lewis, Karen K., 1999. Trying to explain home bias in equities and consumption. Journal of Economic Literature 37, 571-608.

[21] Longin, F., Solnik, Bruno, 1995. Is the Correlation in International Equity Returns Constant: 1960-1990? Journal of International Money and Finance 14, 3-26.

[22] Longin, F., Solnik, Bruno, 2001. Extreme Correlation of International Equity Markets Journal of Finance 56, 649-676.

[23] Lucas, Robert E., 1985. Models of Business Cycles. Basil Blackwell.

[24] Lucas, Robert E., 2003. Macroeconomic Priorities. American Economic Review 93, 1-14.

[25] Newey, Whitney K, West, Kenneth D, 1987. A Simple, Positive Semi-definite, Heteroskedasticity and Autocorrelation Consistent Covariance Matrix. Econometrica 55, 703-708

[26] Obstfeld, Maurice, 1994. Are industrial-country consumption risks globally diversified? In: Leiderman, L., Razin, A. (Eds.), Capital Mobility: The Impact of Consumption, Investment and Growth. Cambridge University Press, New York, pp. 13-47. 
[27] Obstfeld, Maurice, Rogoff, Kenneth S., 1996. Foundations of International Macroeconomics. MIT Press.

[28] Obstfeld, Maurice, Taylor, Alan M., 2004. Global Capital Markets: Integration, Crisis, and Growth. Cambridge University Press.

[29] Reinhart, Carmen M., and Kenneth S. Rogoff, 2009. This Time Is Different: Eight Centuries of Financial Folly. Princeton, New Jersey: Princeton University Press.

[30] Pukthuanthong, Kuntara, Roll, Richard, 2009. Global market integration: An alternative measure and its application. Journal of Financial Economics 94, 214-232.

[31] Quinn, Dennis, Voth, Hans-Joachim, 2008. A Century of Global Equity Market Correlations. American Economic Review. Papers and Proceedings 98, 535-40.

[32] Schularick, Moritz, Steger, Thomas M., 2010. Financial Integration, Investment, and Economic Growth. Evidence From Two Eras of Financial Globalization. Review of Economics and Statistics 92, 756-768. Forthcoming.

[33] Sørensen, Bent E., Yosha, Oved, 1998. International risk sharing and European monetary unification. Journal of International Economics 45, 211-238.

[34] Sørensen, Bent E., Yosha, Oved, Østergaard, Charlotte, 2002. Consumption and Aggregate Constraints: Evidence from US States and Canadian Provinces. Journal of Political Economy 110, 634-645.

[35] Sørensen, Bent E., Yosha, Oved, Wu, Yi-Tsung, Zhu, Yu, 2007. Home bias and international risk sharing: twin puzzles separated at birth. Journal of International Money and Finance 26 (4), 587-605.

[36] Stiglitz, Joseph E., 2000. Capital Market Liberalization, Economic Growth, and Instability. World Development 28, 1075-1086.

[37] Storesletten, Kjetil, Chris I. Telmer, Amir Yaron, 2004. Cyclical Dynamics in Idiosyncratic Labor Market Risk. Journal of Political Economy 112, 695-717.

[38] Tesar, Linda, 1995. Evaluating the Gains from International Risksharing. CarnegieRochester Conference Series on Public Policy 42, 95-143. 
Table 1. Descriptive statistics of country data

This table reports the mean and standard deviation of real per capita consumption growth $(\Delta c)$, real per capita GDP growth $(\Delta y)$, and stock returns $(r)$. We also report the first available observation for each category. Numbers in brackets are t-statistics based on Newey and West (1987) HAC standard errors.

\begin{tabular}{|c|c|c|c|c|c|c|c|c|c|}
\hline & \multicolumn{3}{|c|}{ Cons. growth } & \multicolumn{3}{|c|}{ GDP growth } & \multicolumn{3}{|c|}{ Stock returns } \\
\hline & START & MEAN & STD & START & MEAN & STD & START & MEAN & STD \\
\hline Australia & 1902 & $\begin{array}{r}1.54 \\
{[3.61]}\end{array}$ & 3.88 & 1875 & $\begin{array}{r}1.50 \\
{[4.40]}\end{array}$ & 3.54 & 1876 & $\begin{array}{l}12.44 \\
{[9.35]}\end{array}$ & 18.59 \\
\hline Belgium & 1914 & $\begin{array}{r}1.63 \\
{[2.28]}\end{array}$ & 5.80 & 1875 & $\begin{array}{r}1.66 \\
{[4.87]}\end{array}$ & 2.98 & 1900 & $\begin{array}{r}8.88 \\
{[3.78]}\end{array}$ & 23.90 \\
\hline Canada & 1875 & $\begin{array}{r}2.03 \\
{[5.71]}\end{array}$ & 3.80 & 1875 & $\begin{array}{r}2.11 \\
{[4.80]}\end{array}$ & 4.47 & 1900 & $\begin{array}{l}11.12 \\
{[7.32]}\end{array}$ & 16.97 \\
\hline Denmark & 1875 & $\begin{array}{r}1.45 \\
{[5.50]}\end{array}$ & 3.66 & 1875 & $\begin{array}{r}1.90 \\
{[8.16]}\end{array}$ & 2.85 & 1900 & $\begin{array}{l}10.37 \\
{[5.91]}\end{array}$ & 19.42 \\
\hline France & 1875 & $\begin{array}{r}1.62 \\
{[3.72]}\end{array}$ & 4.14 & 1875 & $\begin{array}{r}1.92 \\
{[4.99]}\end{array}$ & 3.96 & 1875 & $\begin{array}{r}9.03 \\
{[4.79]}\end{array}$ & 22.71 \\
\hline Germany & 1875 & $\begin{array}{r}1.72 \\
{[3.19]}\end{array}$ & 4.50 & 1875 & $\begin{array}{r}2.52 \\
{[4.47]}\end{array}$ & 4.64 & 1875 & $\begin{array}{r}9.24 \\
{[3.61]}\end{array}$ & 28.78 \\
\hline Italy & 1875 & $\begin{array}{r}1.52 \\
{[4.18]}\end{array}$ & 2.94 & 1875 & $\begin{array}{r}2.15 \\
{[6.55]}\end{array}$ & 2.84 & 1900 & $\begin{array}{r}8.75 \\
{[3.32]}\end{array}$ & 28.34 \\
\hline Japan & 1875 & $\begin{array}{r}2.42 \\
{[4.31]}\end{array}$ & 4.29 & 1875 & $\begin{array}{r}2.94 \\
{[5.87]}\end{array}$ & 4.75 & 1900 & $\begin{array}{l}13.01 \\
{[4.80]}\end{array}$ & 27.60 \\
\hline Netherlands & 1875 & $\begin{array}{r}1.43 \\
{[3.37]}\end{array}$ & 3.95 & 1875 & $\begin{array}{r}1.62 \\
{[4.34]}\end{array}$ & 3.26 & 1900 & $\begin{array}{l}10.71 \\
{[5.83]}\end{array}$ & 19.69 \\
\hline Norway & 1875 & $\begin{array}{r}1.82 \\
{[7.53]}\end{array}$ & 2.53 & 1875 & $\begin{array}{r}2.23 \\
{[8.10]}\end{array}$ & 2.68 & 1900 & $\begin{array}{r}9.99 \\
{[4.33]}\end{array}$ & 23.95 \\
\hline South Africa & 1947 & $\begin{array}{r}1.41 \\
{[3.49]}\end{array}$ & 2.49 & 1912 & $\begin{array}{r}1.30 \\
{[2.81]}\end{array}$ & 3.57 & 1900 & $\begin{array}{l}11.08 \\
{[5.05]}\end{array}$ & 23.67 \\
\hline Spain & 1875 & $\begin{array}{r}1.98 \\
{[4.52]}\end{array}$ & 5.44 & 1875 & $\begin{array}{r}2.01 \\
{[5.79]}\end{array}$ & 3.34 & 1875 & $\begin{array}{r}8.63 \\
{[3.97]}\end{array}$ & 21.94 \\
\hline Sweden & 1875 & $\begin{array}{r}1.78 \\
{[7.06]}\end{array}$ & 3.44 & 1875 & $\begin{array}{r}2.28 \\
{[10.72]}\end{array}$ & 2.67 & 1900 & $\begin{array}{l}14.16 \\
{[6.84]}\end{array}$ & 23.94 \\
\hline Switzerland & 1875 & $\begin{array}{r}1.19 \\
{[4.26]}\end{array}$ & 4.07 & 1875 & $\begin{array}{r}1.52 \\
{[5.20]}\end{array}$ & 3.42 & 1900 & $\begin{array}{r}9.44 \\
{[5.97]}\end{array}$ & 17.37 \\
\hline U.K. & 1875 & $\begin{array}{r}1.30 \\
{[5.41]}\end{array}$ & 2.13 & 1875 & $\begin{array}{r}1.47 \\
{[5.93]}\end{array}$ & 2.46 & 1875 & $\begin{array}{r}9.19 \\
{[6.27]}\end{array}$ & 16.67 \\
\hline U.S. & 1875 & $\begin{array}{r}1.85 \\
{[6.73]}\end{array}$ & 3.07 & 1875 & $\begin{array}{r}2.12 \\
{[5.63]}\end{array}$ & 4.06 & 1875 & $\begin{array}{l}10.43 \\
{[8.07]}\end{array}$ & 16.93 \\
\hline
\end{tabular}


Table 2. GDP weights

This table reports average GDP weights over different subsamples.

\begin{tabular}{lrrrrrr}
\hline & 1875 & 1901 & 1926 & 1951 & 1976 & 2001 \\
& -1900 & 1925 & -1950 & -1975 & -2000 & -2012 \\
\hline Australia & 1.56 & 1.60 & 1.75 & 1.87 & 2.01 & 2.36 \\
Belgium & 2.64 & 2.12 & 1.69 & 1.32 & 1.19 & 1.12 \\
Canada & 1.40 & 2.12 & 2.61 & 3.34 & 3.58 & 3.80 \\
Denmark & 0.74 & 0.80 & 0.88 & 0.82 & 0.68 & 0.62 \\
France & 12.71 & 9.22 & 7.30 & 7.20 & 7.03 & 6.52 \\
Germany & 14.86 & 13.86 & 12.02 & 10.49 & 9.21 & 7.86 \\
Italy & 6.74 & 6.51 & 5.61 & 6.18 & 6.29 & 5.42 \\
Japan & 5.01 & 5.42 & 6.42 & 9.26 & 14.85 & 13.40 \\
Netherlands & 1.93 & 1.75 & 1.85 & 1.92 & 1.81 & 1.85 \\
Norway & 0.44 & 0.41 & 0.50 & 0.52 & 0.56 & 0.60 \\
South Africa & 0.00 & 0.00 & 1.10 & 1.12 & 1.05 & 1.02 \\
Spain & 3.95 & 2.94 & 2.46 & 2.39 & 3.15 & 3.55 \\
Sweden & 1.12 & 1.13 & 1.36 & 1.34 & 1.05 & 1.00 \\
Switzerland & 1.18 & 1.13 & 1.20 & 1.34 & 0.99 & 0.85 \\
UK & 18.99 & 15.30 & 12.50 & 8.74 & 6.49 & 6.54 \\
US & 26.75 & 35.60 & 41.42 & 41.90 & 39.75 & 42.98 \\
\hline
\end{tabular}


Table 3. Predictive regressions

This table shows results for predictive regressions of risk sharing on market integration (crosssectional return dispersion of stock returns):

$$
\overline{\text { Risk sharing }}_{t+h}=\alpha_{h}+\gamma_{h} \overline{\text { Market integration }}_{t+1-k}+\varepsilon_{t+h} \text {. }
$$

in the left part of the table and results for the reverse regression

$$
\overline{\text { Market integration }}_{t+h}=\alpha_{h}^{\prime}+\delta_{h} \overline{\text { Risk sharing }}_{t+1-k}+\varepsilon_{t+h}^{\prime} \text {. }
$$

in the right part of the table. The forecast horizon ranges from $h=1,3,5$ to $h=10$ years and we use lagged moving averages of financial market integration measures (or risk sharing measures) over the last $k=1,2,5,10$ years to forecast future averages of the consumption risk sharing (or financial market integration) measure. We report the slope coefficients $\gamma_{h}$ of the predictive regressions, t-statistics based on Newey and West (1987) standard errors

\begin{tabular}{|c|c|c|c|c|c|c|c|c|c|c|c|}
\hline \multicolumn{7}{|c|}{ Dependent: Risk Sharing } & \multicolumn{5}{|c|}{ Dependent: Market Integration } \\
\hline & & \multicolumn{4}{|c|}{ Forecast horizon $h$ in years } & \multirow[b]{2}{*}{$k$} & & \multicolumn{4}{|c|}{ Forecast horizon $h$ in years } \\
\hline \multicolumn{2}{|l|}{$k$} & 1 & 3 & 5 & 10 & & & 1 & 3 & 5 & 10 \\
\hline \multirow[t]{4}{*}{1} & $\gamma_{h}$ & 0.13 & 0.31 & 0.69 & 1.36 & 1 & $\delta_{h}$ & 0.14 & 0.11 & -0.17 & -0.21 \\
\hline & $t_{N W}$ & {$[1.43]$} & {$[1.26]$} & {$[1.90]$} & {$[2.65]$} & & $t_{N W}$ & {$[1.71]$} & {$[0.39]$} & {$[-0.31]$} & {$[-0.19]$} \\
\hline & $t_{H}$ & {$[1.46]$} & {$[1.51]$} & {$[2.11]$} & {$[2.60]$} & & $t_{H}$ & {$[1.65]$} & {$[0.60]$} & {$[-0.65]$} & {$[-0.55]$} \\
\hline & $R^{2}$ & 0.02 & 0.02 & 0.06 & 0.10 & & $R^{2}$ & 0.02 & 0.00 & 0.00 & 0.00 \\
\hline \multirow[t]{4}{*}{2} & $\gamma_{h}$ & 0.13 & 0.40 & 0.82 & 1.59 & 2 & $\delta_{h}$ & 0.08 & -0.01 & -0.33 & -0.31 \\
\hline & $t_{N W}$ & {$[1.26]$} & {$[1.53]$} & {$[2.08]$} & {$[2.83]$} & & $t_{N W}$ & {$[0.76]$} & {$[-0.04]$} & {$[-0.46]$} & {$[-0.21]$} \\
\hline & $t_{H}$ & {$[1.35]$} & {$[1.76]$} & {$[2.23]$} & {$[2.65]$} & & $t_{H}$ & {$[0.87]$} & {$[-0.07]$} & {$[-1.02]$} & {$[-0.62]$} \\
\hline & $R^{2}$ & 0.02 & 0.04 & 0.09 & 0.14 & & $R^{2}$ & 0.01 & 0.00 & 0.01 & 0.00 \\
\hline \multirow[t]{4}{*}{5} & $\gamma_{h}$ & 0.19 & 0.64 & 1.18 & 1.93 & 5 & $\delta_{h}$ & -0.02 & -0.24 & -0.48 & -0.38 \\
\hline & $t_{N W}$ & {$[2.00]$} & {$[2.42]$} & {$[2.86]$} & {$[2.94]$} & & $t_{N W}$ & {$[-0.18]$} & {$[-0.47]$} & {$[-0.51]$} & {$[-0.20]$} \\
\hline & $t_{H}$ & {$[2.05]$} & {$[2.45]$} & {$[2.95]$} & {$[2.84]$} & & $t_{H}$ & {$[-0.23]$} & {$[-0.88]$} & {$[-1.18]$} & {$[-0.59]$} \\
\hline & $R^{2}$ & 0.04 & 0.10 & 0.18 & 0.21 & & $R^{2}$ & 0.00 & 0.01 & 0.02 & 0.00 \\
\hline \multirow[t]{4}{*}{10} & $\gamma_{h}$ & 0.27 & 0.78 & 1.28 & 2.08 & 10 & $\delta_{h}$ & -0.03 & -0.12 & -0.20 & -0.06 \\
\hline & $t_{N W}$ & {$[2.96]$} & {$[3.07]$} & {$[2.93]$} & {$[2.74]$} & & $t_{N W}$ & {$[-0.26]$} & {$[-0.24]$} & {$[-0.23]$} & {$[-0.03]$} \\
\hline & $t_{H}$ & {$[2.94]$} & [3.03] & {$[3.07]$} & {$[2.96]$} & & $t_{H}$ & {$[-0.35]$} & {$[-0.42]$} & {$[-0.46]$} & {$[-0.08]$} \\
\hline & $R^{2}$ & 0.07 & 0.15 & 0.20 & 0.24 & & $R^{2}$ & 0.00 & 0.00 & 0.00 & 0.00 \\
\hline
\end{tabular}
$\left(t_{N W}\right)$, Hodrick (1992) standard errors $\left(t_{H}\right)$, and predictive $R^{2}$ s. 
Table 4. Predictive regressions: Exchange rate volatility and trade integration

This table is similar to Table 3 but here we orthogonalize risk sharing with respect to exchange rate volatility and trade openness changes, i.e. we first regress (the negative of) exchange rate volatility on changes in trade openness. We then regress capital market integration on trade openness differences and FX vol and use the residual of this regression as our measure of capital market integration. We then run predictive regressions of the form

$$
\overline{\text { Risk sharing }}_{t+h}=\alpha_{h}++\tau_{h} \overline{\Delta \text { Trade openness }}_{t+1-k}+\kappa_{h} \overline{\Delta \mathrm{FX}}_{t+1-k}+\gamma_{h} \overline{\text { Market integration }}_{t+1-k}+\varepsilon_{t+h}
$$

where $h$ denotes the forecast horizon in years and $k$ denotes the number of years over which we form the moving average of the RHS variables. We only report results for $k=1,5,10$ to conserve space. The sample period is $1900-2012$.

\begin{tabular}{|c|c|c|c|c|c|c|c|}
\hline \multirow[b]{2}{*}{$k$} & & \multicolumn{6}{|c|}{ Forecast horizon (years) } \\
\hline & & 1 & 2 & 3 & 4 & 5 & 10 \\
\hline \multirow[t]{10}{*}{1} & $\tau$ & 0.02 & -0.03 & 0.21 & 0.45 & 0.63 & -1.53 \\
\hline & $t_{N W}$ & {$[0.14]$} & {$[-0.12]$} & {$[0.64]$} & {$[1.09]$} & [1.17] & {$[-2.43]$} \\
\hline & $t_{H}$ & {$[0.17]$} & {$[-0.14]$} & {$[0.69]$} & [1.11] & [1.29] & {$[-2.68]$} \\
\hline & $\kappa$ & 0.12 & 0.19 & 0.04 & -0.12 & -0.22 & -0.15 \\
\hline & $t_{N W}$ & [1.28] & {$[1.14]$} & {$[0.19]$} & {$[-0.45]$} & {$[-0.68]$} & {$[-0.24]$} \\
\hline & $t_{H}$ & [1.18] & {$[1.09]$} & {$[0.18]$} & {$[-0.46]$} & {$[-0.70]$} & {$[-0.30]$} \\
\hline & $\gamma$ & 0.14 & 0.28 & 0.18 & 0.27 & 0.40 & 1.01 \\
\hline & $t_{N W}$ & [1.35] & {$[1.43]$} & {$[0.65]$} & {$[0.81]$} & {$[1.07]$} & {$[2.31]$} \\
\hline & $t_{H}$ & [1.35] & {$[1.58]$} & {$[0.78]$} & [0.98] & {$[1.28]$} & [2.11] \\
\hline & $R^{2}$ & -0.01 & 0.00 & -0.01 & 0.02 & 0.05 & 0.11 \\
\hline \multirow[t]{10}{*}{5} & $\tau$ & 0.16 & 0.35 & 0.52 & 0.55 & 0.51 & -2.46 \\
\hline & $t_{N W}$ & [1.09] & {$[1.51]$} & {$[1.73]$} & [1.49] & {$[0.92]$} & {$[-2.26]$} \\
\hline & $t_{H}$ & {$[0.94]$} & [1.19] & {$[1.32]$} & [1.14] & {$[0.95]$} & {$[-3.56]$} \\
\hline & $\kappa$ & -0.07 & -0.17 & -0.25 & -0.14 & 0.04 & 1.21 \\
\hline & $t_{N W}$ & {$[-0.58]$} & {$[-0.72]$} & {$[-0.73]$} & {$[-0.33]$} & {$[0.09]$} & [1.48] \\
\hline & $t_{H}$ & {$[-0.60]$} & {$[-0.75]$} & {$[-0.80]$} & {$[-0.35]$} & {$[0.10]$} & {$[1.56]$} \\
\hline & $\gamma$ & 0.10 & 0.19 & 0.37 & 0.78 & 1.19 & 2.47 \\
\hline & $t_{N W}$ & {$[0.67]$} & {$[0.72]$} & {$[0.97]$} & [1.63] & {$[2.14]$} & [3.31] \\
\hline & $t_{H}$ & {$[0.74]$} & {$[0.78]$} & {$[1.07]$} & {$[1.71]$} & {$[2.17]$} & {$[2.81]$} \\
\hline & $R^{2}$ & 0.02 & 0.06 & 0.11 & 0.15 & 0.17 & 0.30 \\
\hline \multirow[t]{10}{*}{10} & $\tau$ & -0.07 & -0.07 & -0.08 & -0.14 & -0.36 & -2.92 \\
\hline & $t_{N W}$ & {$[-0.47]$} & {$[-0.26]$} & {$[-0.20]$} & {$[-0.25]$} & {$[-0.46]$} & {$[-3.00]$} \\
\hline & $t_{H}$ & {$[-0.52]$} & {$[-0.30]$} & {$[-0.24]$} & {$[-0.32]$} & {$[-0.69]$} & {$[-3.33]$} \\
\hline & $\kappa$ & 0.15 & 0.31 & 0.47 & 0.75 & 1.11 & 3.11 \\
\hline & $t_{N W}$ & [1.48] & {$[1.53]$} & {$[1.47]$} & [1.74] & {$[2.15]$} & {$[4.52]$} \\
\hline & $t_{H}$ & [1.33] & {$[1.40]$} & {$[1.44]$} & {$[1.71]$} & {$[2.00]$} & {$[2.81]$} \\
\hline & $\gamma$ & 0.37 & 0.77 & 1.14 & 1.63 & 2.12 & 4.07 \\
\hline & $t_{N W}$ & {$[3.07]$} & {$[3.35]$} & {$[3.36]$} & [3.67] & {$[4.06]$} & [4.91] \\
\hline & $t_{H}$ & {$[2.72]$} & {$[2.86]$} & {$[2.91]$} & {$[3.14]$} & {$[3.26]$} & {$[3.41]$} \\
\hline & $R^{2}$ & 0.05 & 0.11 & 0.15 & 0.21 & 0.27 & 0.62 \\
\hline
\end{tabular}


Table 5. Predictive regressions: Post Bretton Woods

This table is similar to Table 4 and shows results for the regression

$\overline{\text { Risk sharing }}_{t+h}=\alpha_{h}+\tau_{h} \overline{\Delta \text { Trade openness }}_{t+1-k}+\kappa_{h} \overline{\Delta \mathrm{FX} \mathrm{vol}}_{t+1-k}+\gamma_{h} \overline{\text { Market integration }}_{t+1-k}+\varepsilon_{t+h}$. but here we limit the sample to the post Bretton Woods period.

\begin{tabular}{|c|c|c|c|c|c|c|c|}
\hline \multirow[b]{2}{*}{$k$} & & \multicolumn{6}{|c|}{ Forecast horizon (years) } \\
\hline & & 1 & 2 & 3 & 4 & 5 & 10 \\
\hline \multirow[t]{10}{*}{1} & $\tau$ & 0.07 & 0.13 & 0.60 & 1.19 & 1.74 & 0.19 \\
\hline & $t_{N W}$ & {$[0.31]$} & {$[0.38]$} & {$[1.48]$} & {$[2.16]$} & {$[2.21]$} & {$[0.35]$} \\
\hline & $t_{H}$ & {$[0.35]$} & {$[0.39]$} & {$[1.38]$} & {$[2.10]$} & {$[2.55]$} & {$[0.43]$} \\
\hline & $\kappa$ & -0.15 & 0.09 & -0.01 & -0.46 & -0.30 & -0.08 \\
\hline & $t_{N W}$ & {$[-0.86]$} & {$[0.37]$} & {$[-0.04]$} & {$[-1.87]$} & {$[-1.20]$} & {$[-0.33]$} \\
\hline & $t_{H}$ & {$[-0.66]$} & {$[0.40]$} & {$[-0.05]$} & {$[-1.42]$} & {$[-0.90]$} & {$[-0.16]$} \\
\hline & $\gamma$ & 0.13 & 0.42 & 0.31 & 0.09 & 0.32 & 1.26 \\
\hline & $t_{N W}$ & {$[0.79]$} & {$[1.37]$} & {$[0.70]$} & {$[0.21]$} & {$[0.78]$} & {$[3.02]$} \\
\hline & $t_{H}$ & {$[0.82]$} & [1.69] & {$[0.92]$} & {$[0.22]$} & {$[0.72]$} & {$[3.11]$} \\
\hline & $R^{2}$ & -0.02 & -0.03 & 0.03 & 0.22 & 0.36 & 0.03 \\
\hline \multirow[t]{10}{*}{5} & $\tau$ & 0.48 & 0.97 & 1.44 & 1.72 & 2.47 & 1.55 \\
\hline & $t_{N W}$ & {$[3.19]$} & [4.13] & {$[4.84]$} & {$[4.11]$} & {$[10.67]$} & {$[2.15]$} \\
\hline & $t_{H}$ & {$[1.74]$} & [1.94] & {$[2.15]$} & {$[2.22]$} & {$[2.97]$} & {$[1.34]$} \\
\hline & $\kappa$ & -0.41 & -0.53 & -0.64 & -0.32 & 0.54 & 1.41 \\
\hline & $t_{N W}$ & {$[-2.28]$} & {$[-1.74]$} & {$[-1.98]$} & {$[-0.81]$} & {$[1.27]$} & [3.65] \\
\hline & $t_{H}$ & {$[-1.40]$} & {$[-1.03]$} & {$[-0.97]$} & {$[-0.41]$} & {$[0.65]$} & {$[0.73]$} \\
\hline & $\gamma$ & -0.39 & -0.44 & -0.38 & 0.22 & 1.30 & 3.11 \\
\hline & $t_{N W}$ & {$[-1.43]$} & {$[-1.08]$} & {$[-1.00]$} & {$[0.45]$} & {$[2.31]$} & [4.67] \\
\hline & $t_{H}$ & {$[-1.47]$} & {$[-0.95]$} & {$[-0.66]$} & {$[0.38]$} & {$[2.20]$} & [7.42] \\
\hline & $R^{2}$ & 0.27 & 0.42 & 0.58 & 0.63 & 0.79 & 0.41 \\
\hline \multirow[t]{10}{*}{10} & $\tau$ & 0.40 & 0.93 & 1.53 & 1.95 & 3.88 & 4.69 \\
\hline & $t_{N W}$ & {$[1.45]$} & {$[2.46]$} & {$[3.38]$} & {$[2.67]$} & {$[4.87]$} & {$[2.71]$} \\
\hline & $t_{H}$ & {$[1.28]$} & {$[1.84]$} & {$[2.38]$} & [2.41] & {$[4.20]$} & {$[3.00]$} \\
\hline & $\kappa$ & -0.42 & -0.49 & -0.91 & -0.34 & 2.44 & 1.90 \\
\hline & $t_{N W}$ & {$[-0.66]$} & {$[-0.55]$} & {$[-0.87]$} & {$[-0.25]$} & {$[4.75]$} & {$[2.81]$} \\
\hline & $t_{H}$ & {$[-0.64]$} & {$[-0.49]$} & {$[-0.76]$} & {$[-0.23]$} & {$[1.44]$} & {$[0.87]$} \\
\hline & $\gamma$ & -0.34 & -0.30 & -0.67 & 0.13 & 3.02 & 2.46 \\
\hline & $t_{N W}$ & {$[-0.51]$} & {$[-0.33]$} & {$[-0.57]$} & {$[0.09]$} & {$[4.21]$} & [3.09] \\
\hline & $t_{H}$ & {$[-0.46]$} & {$[-0.26]$} & {$[-0.50]$} & [0.09] & {$[1.87]$} & [1.99] \\
\hline & $R^{2}$ & 0.08 & 0.22 & 0.32 & 0.36 & 0.58 & 0.56 \\
\hline
\end{tabular}


Table 6. Predictive regressions: Permanent component

This table is similar to Table 4 and shows results for the regression

$\overline{\text { Risk sharing }}_{t+h}=\alpha_{h}+\tau_{h} \overline{\Delta \text { Trade openness }}_{t+1-k}+\kappa_{h} \overline{\Delta \mathrm{FX} \mathrm{vol}}_{t+1-k}+\gamma_{h} \overline{\text { Market integration }}_{t+1-k}+\varepsilon_{t+h}$.

but here the dependent variable (consumption risk sharing) is based on the permanent component of GDP. The sample period is $1900-2012$.

\begin{tabular}{|c|c|c|c|c|c|c|c|}
\hline \multirow[b]{2}{*}{$k$} & & \multicolumn{6}{|c|}{ Forecast horizon (years) } \\
\hline & & 1 & 2 & 3 & 4 & 5 & 10 \\
\hline \multirow[t]{7}{*}{1} & $\tau$ & 0.02 & 0.10 & 0.31 & 0.35 & 0.50 & 0.45 \\
\hline & $t_{H}$ & {$[0.17]$} & {$[0.47]$} & {$[1.14]$} & {$[1.20]$} & {$[1.57]$} & {$[0.92]$} \\
\hline & $\kappa$ & 0.00 & -0.09 & -0.26 & -0.23 & -0.29 & -0.47 \\
\hline & $t_{H}$ & {$[-0.05]$} & {$[-0.54]$} & {$[-1.21]$} & {$[-0.92]$} & {$[-1.01]$} & {$[-0.92]$} \\
\hline & $\gamma$ & -0.01 & -0.03 & -0.14 & -0.12 & -0.08 & -0.62 \\
\hline & $t_{H}$ & {$[-0.07]$} & {$[-0.16]$} & {$[-0.64]$} & {$[-0.47]$} & {$[-0.26]$} & {$[-1.49]$} \\
\hline & $R^{2}$ & -0.03 & -0.02 & 0.05 & 0.03 & 0.06 & 0.06 \\
\hline \multirow[t]{7}{*}{5} & $\tau$ & 0.17 & 0.39 & 0.57 & 0.65 & 0.93 & 1.38 \\
\hline & $t_{H}$ & {$[1.65]$} & {$[2.02]$} & {$[2.23]$} & {$[1.82]$} & {$[2.04]$} & {$[1.91]$} \\
\hline & $\kappa$ & -0.20 & -0.39 & -0.46 & -0.45 & -0.57 & -1.29 \\
\hline & $t_{H}$ & {$[-1.87]$} & {$[-1.88]$} & {$[-1.53]$} & {$[-1.15]$} & {$[-1.20]$} & {$[-1.27]$} \\
\hline & $\gamma$ & -0.18 & -0.35 & -0.39 & -0.40 & -0.53 & -1.76 \\
\hline & $t_{H}$ & {$[-1.39]$} & {$[-1.48]$} & {$[-1.17]$} & {$[-0.95]$} & {$[-1.08]$} & {$[-1.97]$} \\
\hline & $R^{2}$ & 0.01 & 0.07 & 0.12 & 0.11 & 0.18 & 0.38 \\
\hline \multirow[t]{7}{*}{10} & $\tau$ & 0.14 & 0.38 & 0.59 & 0.74 & 1.01 & 1.29 \\
\hline & $t_{H}$ & {$[1.11]$} & {$[1.61]$} & {$[1.77]$} & {$[1.68]$} & {$[1.86]$} & [1.43] \\
\hline & $\kappa$ & -0.24 & -0.48 & -0.64 & -0.75 & -0.88 & -1.72 \\
\hline & $t_{H}$ & {$[-1.82]$} & {$[-1.75]$} & {$[-1.52]$} & {$[-1.33]$} & {$[-1.24]$} & {$[-1.25]$} \\
\hline & $\gamma$ & -0.29 & -0.57 & -0.78 & -0.96 & -1.13 & -2.20 \\
\hline & $t_{H}$ & {$[-2.24]$} & {$[-2.21]$} & {$[-1.93]$} & {$[-1.80]$} & {$[-1.72]$} & {$[-1.85]$} \\
\hline & $R^{2}$ & 0.02 & 0.09 & 0.15 & 0.20 & 0.28 & 0.50 \\
\hline
\end{tabular}


Table 7. Predictive regressions: Transitory component

This table is similar to Table 4 and shows results for the regression

$\overline{\text { Risk sharing }}_{t+h}=\alpha_{h}+\tau_{h} \overline{\Delta \text { Trade openness }}_{t+1-k}+\kappa_{h} \overline{\Delta \mathrm{FX} \mathrm{vol}}_{t+1-k}+\gamma_{h} \overline{\text { Market integration }}_{t+1-k}+\varepsilon_{t+h}$.

but here the dependent variable (consumption risk sharing) is based on the transitory component of GDP.

The sample period is $1900-2012$.

\begin{tabular}{|c|c|c|c|c|c|c|c|}
\hline \multirow[b]{2}{*}{$k$} & & \multicolumn{6}{|c|}{ Forecast horizon (years) } \\
\hline & & 1 & 2 & 3 & 4 & 5 & 10 \\
\hline \multirow[t]{7}{*}{1} & $\tau$ & 0.00 & -0.13 & 0.03 & 0.15 & 0.24 & -1.49 \\
\hline & $t_{H}$ & {$[-0.04]$} & {$[-0.65]$} & {$[0.11]$} & {$[0.44]$} & {$[0.60]$} & {$[-2.78]$} \\
\hline & $\kappa$ & 0.11 & 0.28 & 0.24 & 0.12 & 0.08 & 0.13 \\
\hline & $t_{H}$ & {$[1.04]$} & {$[1.51]$} & {$[0.92]$} & {$[0.38]$} & {$[0.23]$} & {$[0.23]$} \\
\hline & $\gamma$ & 0.01 & 0.15 & 0.11 & 0.16 & 0.26 & 0.87 \\
\hline & $t_{H}$ & [0.10] & {$[0.78]$} & {$[0.45]$} & {$[0.57]$} & {$[0.81]$} & {$[1.78]$} \\
\hline & $R^{2}$ & -0.02 & 0.01 & -0.01 & -0.02 & -0.02 & 0.06 \\
\hline \multirow[t]{7}{*}{5} & $\tau$ & 0.04 & 0.10 & 0.19 & 0.17 & 0.05 & -2.86 \\
\hline & $t_{H}$ & {$[0.30]$} & {$[0.41]$} & {$[0.56]$} & [0.39] & {$[0.09]$} & {$[-4.00]$} \\
\hline & $\kappa$ & 0.03 & 0.09 & 0.09 & 0.21 & 0.41 & 1.39 \\
\hline & $t_{H}$ & {$[0.23]$} & {$[0.35]$} & {$[0.24]$} & {$[0.46]$} & {$[0.75]$} & [1.64] \\
\hline & $\gamma$ & 0.10 & 0.28 & 0.46 & 0.80 & 1.17 & 2.69 \\
\hline & $t_{H}$ & {$[0.74]$} & [1.11] & [1.26] & [1.75] & [2.15] & {$[2.97]$} \\
\hline & $R^{2}$ & -0.02 & 0.00 & 0.03 & 0.07 & 0.10 & 0.35 \\
\hline \multirow[t]{7}{*}{10} & $\tau$ & -0.15 & -0.25 & -0.36 & -0.51 & -0.82 & -3.06 \\
\hline & $t_{H}$ & {$[-1.17]$} & {$[-1.07]$} & {$[-1.06]$} & {$[-1.15]$} & {$[-1.53]$} & {$[-3.47]$} \\
\hline & $\kappa$ & 0.21 & 0.43 & 0.62 & 0.88 & 1.19 & 2.78 \\
\hline & $t_{H}$ & {$[1.54]$} & [1.65] & {$[1.64]$} & {$[1.78]$} & {$[1.97]$} & {$[2.54]$} \\
\hline & $\gamma$ & 0.35 & 0.79 & 1.20 & 1.69 & 2.18 & 4.20 \\
\hline & $t_{H}$ & {$[2.46]$} & {$[2.89]$} & {$[2.95]$} & {$[3.13]$} & {$[3.24]$} & {$[3.45]$} \\
\hline & $R^{2}$ & 0.04 & 0.13 & 0.19 & 0.27 & 0.34 & 0.65 \\
\hline
\end{tabular}


Table 8. Panel regressions: The role of trade openness and exchange rate flexibility This table shows results for panel regressions of consumption growth on GDP growth and (interaction terms of GDP with) changes in trade openness and exchange rate volatility. The latter two are lagged by one year. The panel regression includes both country and time fixed effects and $t$-statistics in brackets are based on standard errors clustered by country and time. The sample period is $1900-2012$. Note that a higher number for the coefficient on $\Delta G D P_{t}$

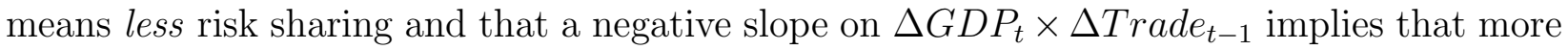
trade openness of a country increases risk sharing.

\begin{tabular}{lrrrr}
\hline & (i) & (ii) & (iii) & (iv) \\
\hline$\Delta G D P_{t}$ & 0.61 & 0.65 & 0.66 & 0.67 \\
& {$[9.96]$} & {$[10.80]$} & {$[9.56]$} & {$[10.47]$} \\
$\Delta$ Trade $_{t-1}$ & & 0.28 & & 0.34 \\
& & {$[2.04]$} & & {$[2.53]$} \\
FX volatility & & & -0.11 & -0.07 \\
& & & {$[-0.91]$} & {$[-0.52]$} \\
$\Delta G D P_{t-1} \times \Delta$ Trade $_{t-1}$ & & -0.06 & & -0.06 \\
& & & & {$[-3.65]$} \\
$\Delta G D P_{t} \times$ FX volatility $_{t-1}$ & & & 0.03 & 0.03 \\
$R^{2}$ & 0.30 & 0.37 & 0.34 & {$[0.66]$} \\
\end{tabular}


Table 9. Panel regressions: The role of crises

This table shows results for panel regressions of consumption growth on GDP growth and interaction terms of GDP with a country-specific crisis indicator ("Crisis") and a global crisis indicator ("Global Crisis") which is based on a GDP-weighted average of country-specific crisis indicators. The country-specific crisis indicators measure the occurence of currency, inflation, debt (external and internal), banking, and other crises and are taken from Reinhart and Rogoff (2009). The indicator we use refers to the "tally" measure in Reinhart and Rogoff, i.e. the crisis indicator can range from 0 (no crisis) to 6 (all of the above mentioned crises occur simultaneously). The panel regression includes country fixed effects and $t$-statistics in brackets are based on standard errors clustered by country and time. The sample period is $1900-2010$ (due to data availability). Note that a higher number for the coefficient on $\Delta G D P_{t}$ means less risk sharing a and that a negative slope on $\Delta G D P_{t} \times$ Global Crisis means that a more severe global crisis increases risk sharing.

\begin{tabular}{|c|c|c|c|c|}
\hline & (i) & (ii) & (iii) & (iv) \\
\hline \multirow[t]{2}{*}{$\Delta G D P_{t}$} & 0.65 & 0.65 & 0.73 & 0.72 \\
\hline & {$[10.59]$} & {$[9.25]$} & {$[10.51]$} & {$[10.16]$} \\
\hline \multirow[t]{2}{*}{ Crisis $_{t}$} & & -0.08 & & -0.12 \\
\hline & & {$[-0.52]$} & & {$[-0.85]$} \\
\hline \multirow[t]{2}{*}{ Global Crisis $_{t}$} & & & 0.21 & 0.22 \\
\hline & & & {$[0.68]$} & {$[0.68]$} \\
\hline \multirow[t]{2}{*}{$\Delta G D P_{t} \times$ Crisis $_{t}$} & & 0.00 & & 0.03 \\
\hline & & {$[-0.02]$} & & {$[0.88]$} \\
\hline \multirow[t]{2}{*}{$\Delta G D P_{t} \times$ Global Crisis $_{t}$} & & & -0.12 & -0.14 \\
\hline & & & {$[-2.92]$} & {$[-2.72]$} \\
\hline$R^{2}$ & 0.35 & 0.35 & 0.35 & 0.35 \\
\hline
\end{tabular}




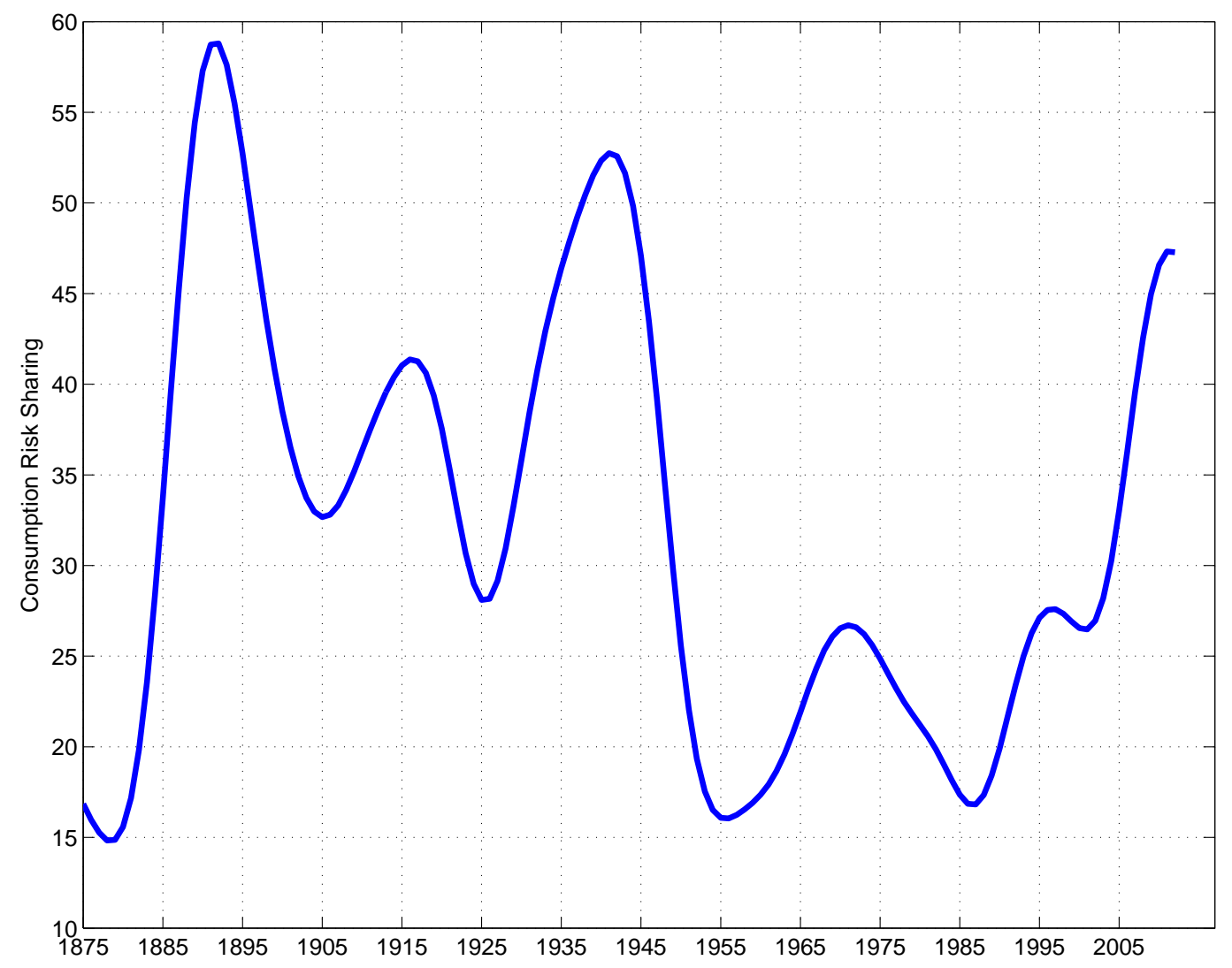

Figure 1. Consumption risk sharing

This figure shows a measure of consumption risk sharing over the period 1875 to 2012 . Results are based on cross-sectional regressions of deviations of log real consumption growth from world consumption growth on a constant and deviations of log real GDP growth from world GDP growth for each year in our sample. The solid (blue) line shows $100-100 \cdot \widehat{\beta}$ where $\beta$ is the slope coefficient in the cross-sectional regressions. We use kernel regression to smooth the estimated $\widehat{\beta} s$. 


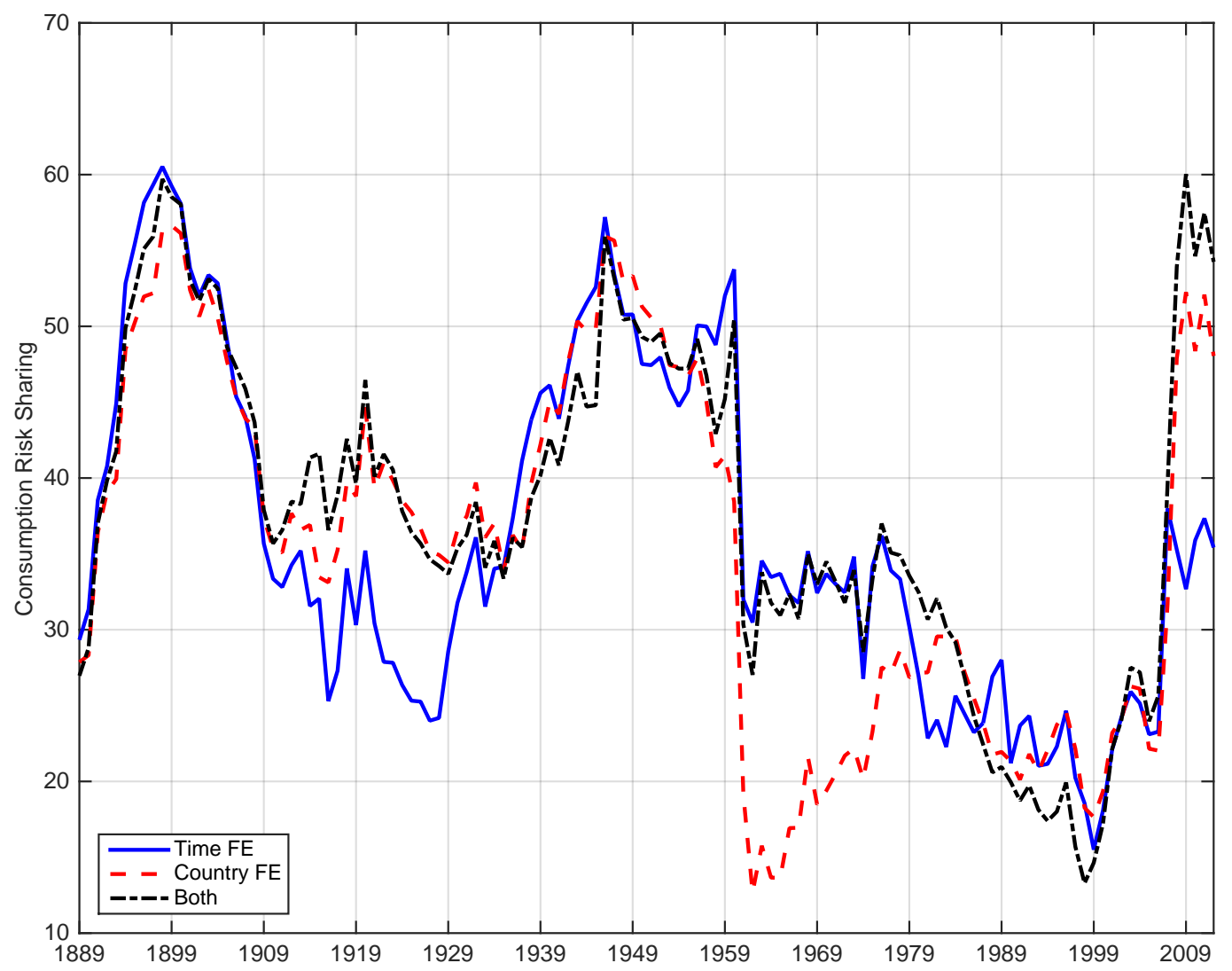

Figure 2. Consumption risk sharing: Rolling panel regressions

This figure shows results from rolling panel regressions (based on a 15-year moving window) of $\log$ real consumption growth on a constant and log real GDP growth. We plot $100-100 \cdot \widehat{\beta}$ where $\beta$ is the slope coefficient on GDP growth in the panel regressions. The solid (blue) line refers to a specification with (yearly) time fixed effects (FE), the dashed (red) line refers to country fixed effects, and the dash-dotted (black) line refers to a specification with both types of fixed effects. 


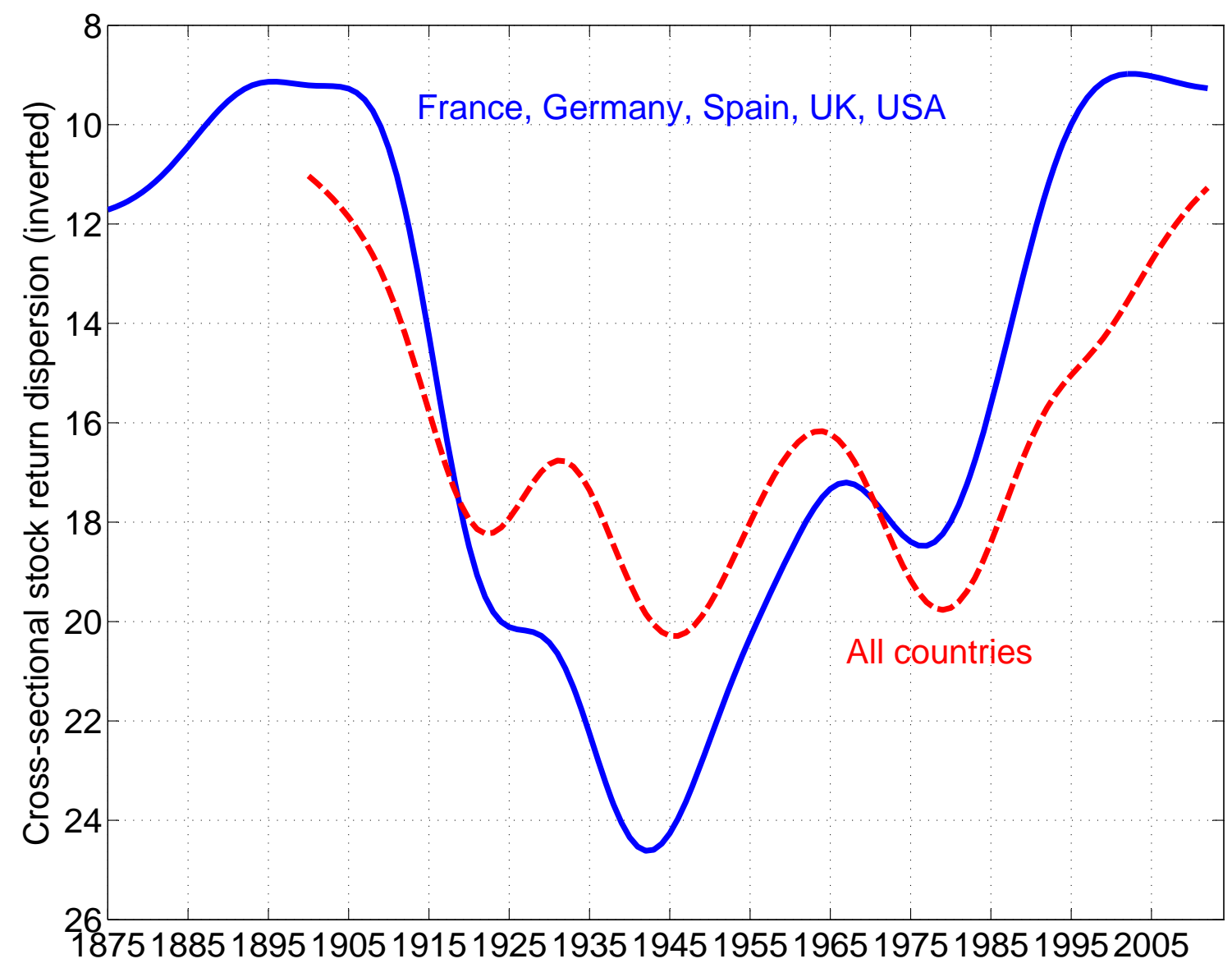

Figure 3. Stock market integration

This figure plots stock market integration over the period 1875 to 2012 based on the crosssectional dispersion in global stock market returns (in USD) for each year in our sample (the scale is inverted).We employ a smoothed time-series based on a kernel regression. The solid line refers to a sample of five countries for which data are available for the full sample period whereas the dashed line refers to all countries. 


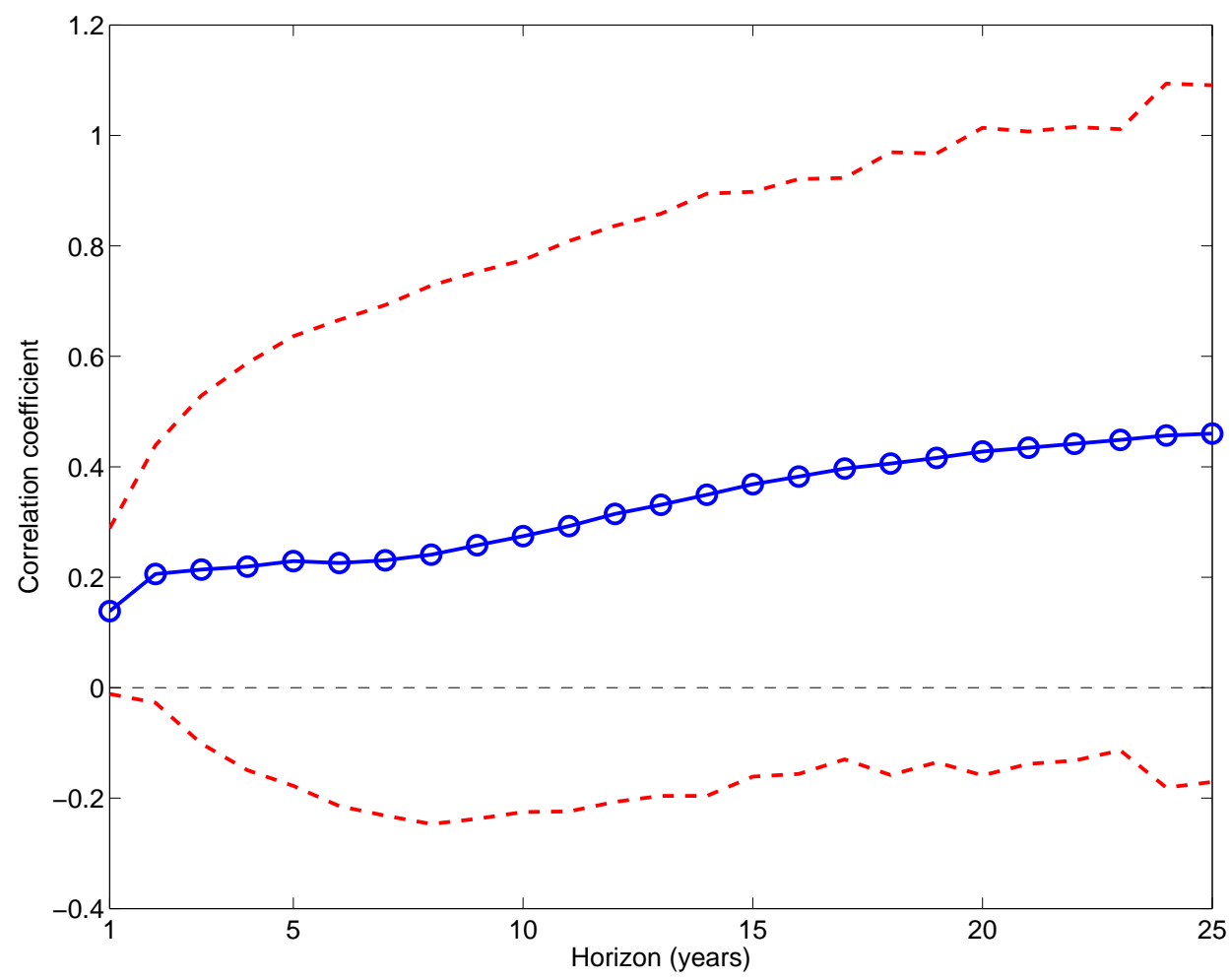

Figure 4. Contemporaneous correlation between risk sharing and market integration

This figure shows the contemporaneous correlation between risk sharing and market integration for different data frequencies (horizons from $1,2, \ldots, 25$ years). For frequencies lower than one year, we employ overlapping yearly data windows. The dashed red lines are $95 \%$ confidence intervals based on a moving block bootstrap (with block size equal to the horizon in years). 


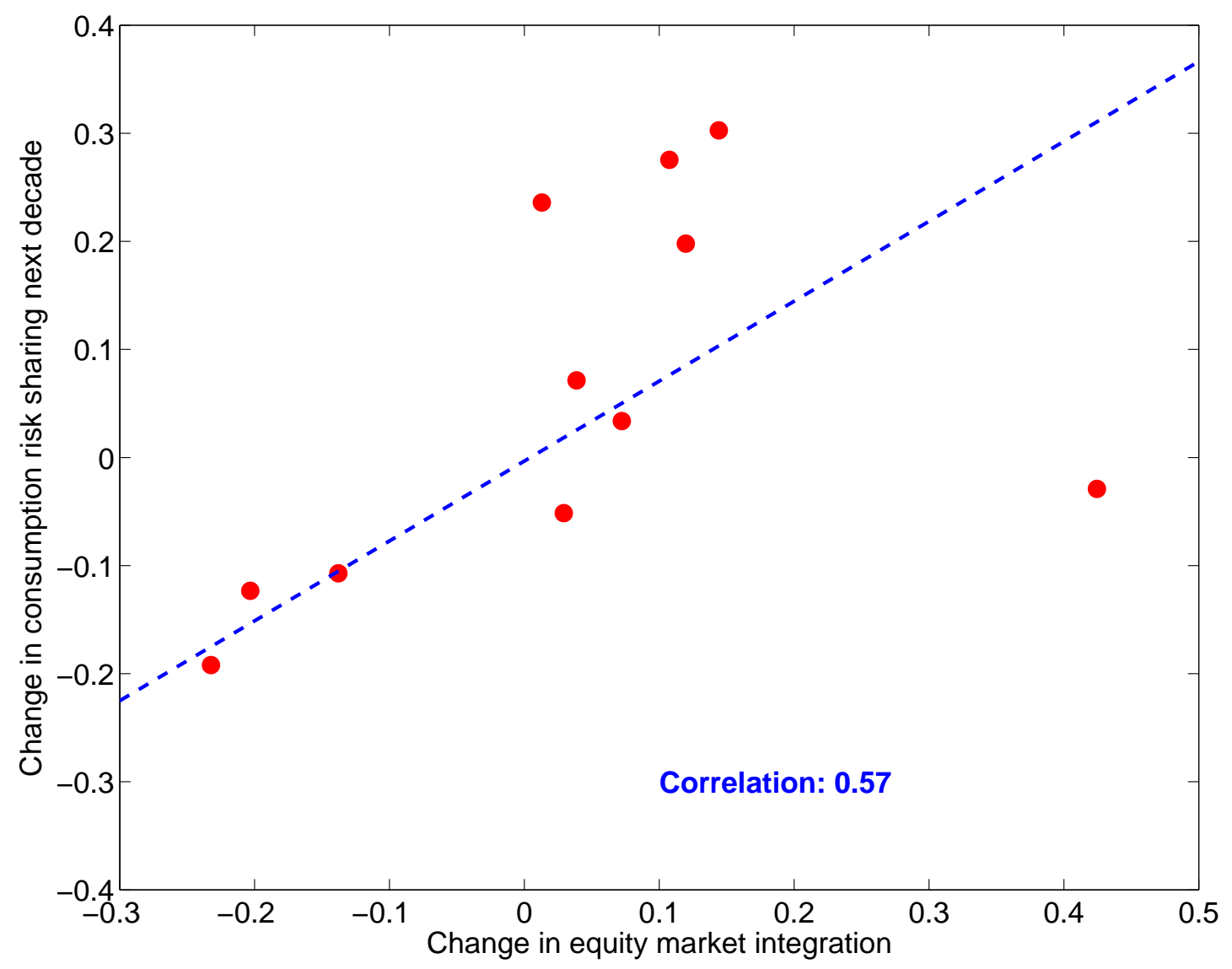

Figure 5. Stock market integration and consumption risk sharing

This figure shows a scatter plot of the change in equity market integration and the change in consumption risk sharing over the next decade. 

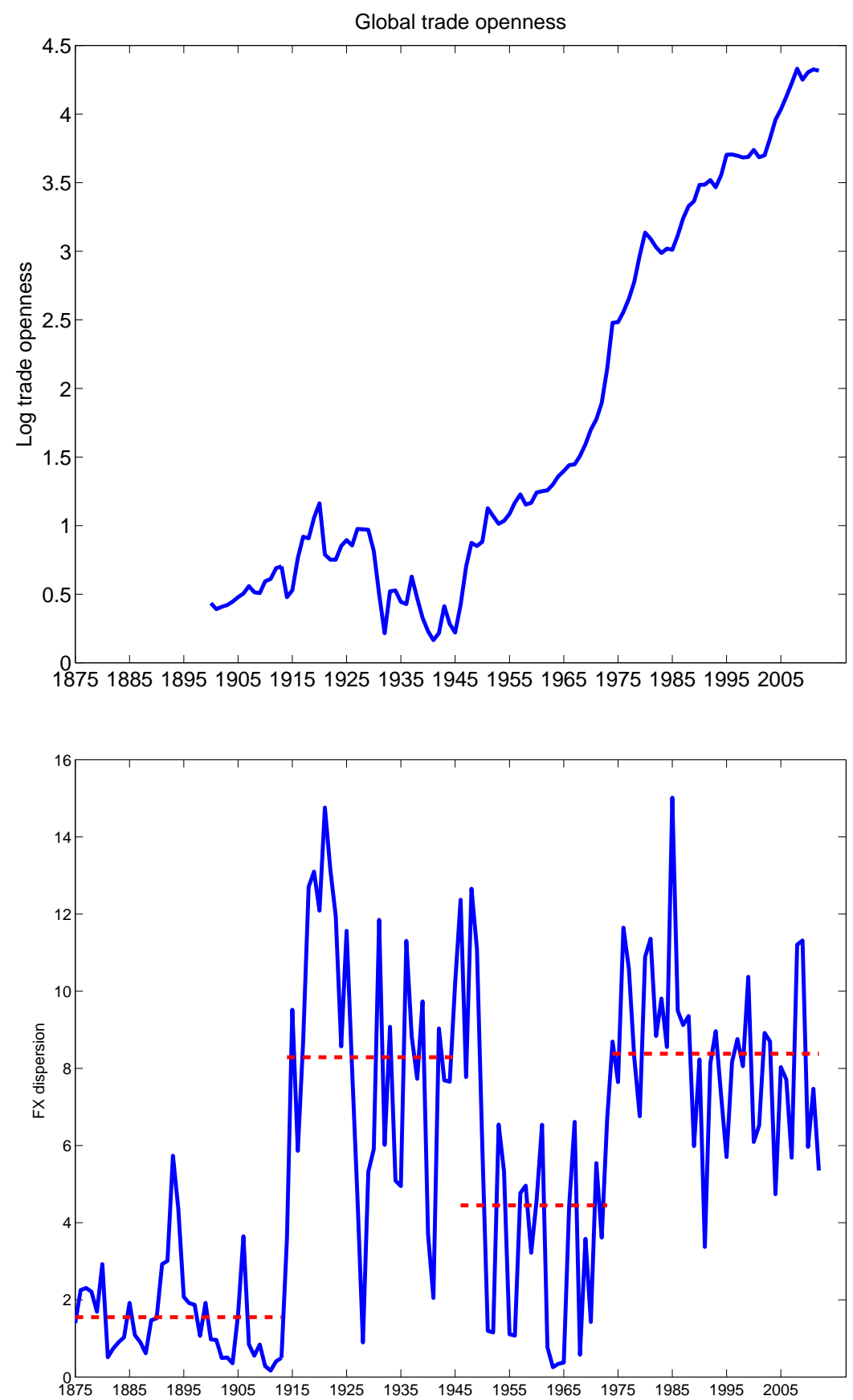

Figure 6. Trade openness and exchange rate flexibility

This figure shows in the top-panel a time-series plot of (log) global trade openness, where trade openness is defined as the sum of exports and imports divided by GDP. The lower panel shows our measure of exchange rate flexibility. 


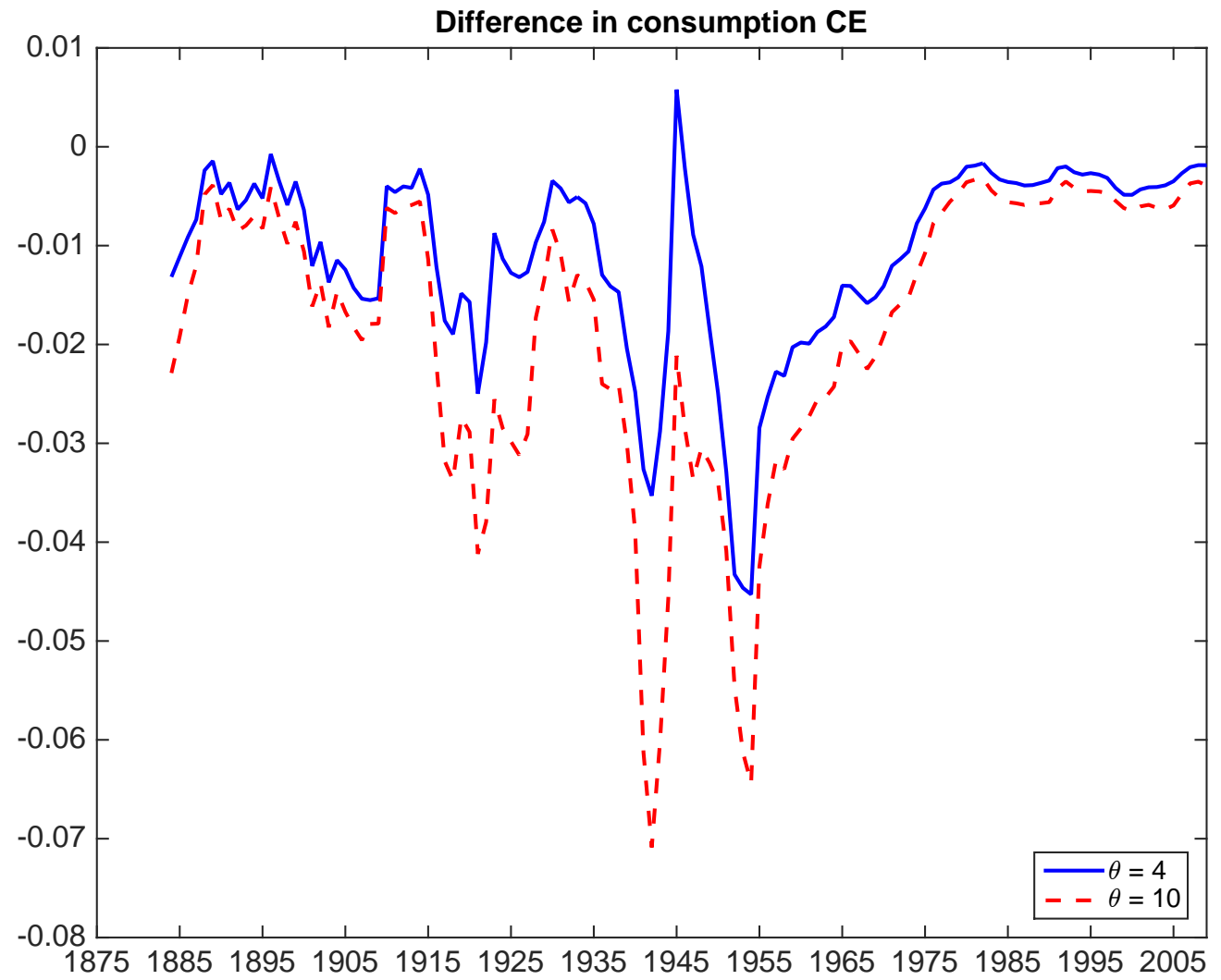

Figure 7. Welfare loss

This figure shows the difference between the GDP-weighted cross-sectional average of consumption certainty equivalence for individual countries over 10-year rolling windows minus the certainty equivalence consumption growth rate of world consumption over the same 10year rolling windows for a CRRA utility function with risk aversion coefficients $\theta=4$ and 10. 
Supplementary Internet Appendix to accompany

\section{Capital Market Integration and Consumption Risk Sharing over the Long Run}


Table A.I. Predictive regressions: Idiosyncratic Volatility

This table is similar to Table 3 but here we employ idiosyncratic volatility as our measure for stock market integration.

\begin{tabular}{|c|c|c|c|c|c|c|c|c|c|c|c|}
\hline \multirow[b]{3}{*}{$k$} & \multicolumn{5}{|c|}{ Dependent: Risk Sharing } & \multicolumn{6}{|c|}{ Dependent: Market Integration } \\
\hline & & \multicolumn{4}{|c|}{ Forecast horizon $h$ in years } & \multirow[b]{2}{*}{$k$} & & \multicolumn{4}{|c|}{ Forecast horizon $h$ in years } \\
\hline & & 1 & 3 & 5 & 10 & & & 1 & 3 & 5 & 10 \\
\hline \multirow[t]{4}{*}{1} & $\gamma_{h}$ & 0.12 & 0.40 & 0.83 & 2.22 & 1 & $\delta_{h}$ & 0.20 & 0.21 & 0.05 & 0.33 \\
\hline & $t_{N W}$ & {$[1.30]$} & {$[1.72]$} & {$[2.51]$} & {$[3.68]$} & & $t_{N W}$ & {$[2.47]$} & {$[0.83]$} & {$[0.10]$} & {$[0.21]$} \\
\hline & $t_{H}$ & $(1.42)$ & $(2.03)$ & $(2.64)$ & $(3.06)$ & & $t_{H}$ & $(2.26)$ & $(1.27)$ & $(0.20)$ & $(0.76)$ \\
\hline & $R^{2}$ & 0.01 & 0.04 & 0.09 & 0.18 & & $R^{2}$ & 0.04 & 0.01 & 0.00 & 0.00 \\
\hline \multirow[t]{4}{*}{2} & $\gamma_{h}$ & 0.15 & 0.53 & 0.97 & 2.59 & 2 & $\delta_{h}$ & 0.12 & 0.09 & -0.05 & 0.29 \\
\hline & $t_{N W}$ & {$[1.54]$} & {$[2.22]$} & {$[2.69]$} & {$[3.53]$} & & $t_{N W}$ & {$[1.30]$} & {$[0.29]$} & {$[-0.07]$} & {$[0.14]$} \\
\hline & $t_{H}$ & (1.70) & $(2.43)$ & (2.78) & $(3.14)$ & & $t$ & $(1.47)$ & $(0.45)$ & $(-0.14)$ & $(0.51)$ \\
\hline & $R^{2}$ & 0.02 & 0.07 & 0.12 & 0.24 & & $R^{2}$ & 0.01 & 0.00 & 0.00 & 0.00 \\
\hline \multirow[t]{4}{*}{5} & $\gamma_{h}$ & 0.23 & 0.73 & 1.31 & 2.90 & 5 & $\delta_{h}$ & 0.05 & 0.02 & 0.05 & 0.66 \\
\hline & $t_{N W}$ & {$[2.56]$} & [3.12] & [3.40] & {$[3.21]$} & & $t_{N W}$ & {$[0.45]$} & {$[0.05]$} & {$[0.05]$} & {$[0.25]$} \\
\hline & $t_{H}$ & (2.59) & $(2.99)$ & $(3.35)$ & $(3.30)$ & & $t_{H}$ & $(0.56)$ & $(0.09)$ & $(0.11)$ & $(0.86)$ \\
\hline & $R^{2}$ & 0.05 & 0.13 & 0.22 & 0.30 & & $R^{2}$ & 0.00 & 0.00 & 0.00 & 0.00 \\
\hline \multirow[t]{4}{*}{10} & $\gamma_{h}$ & 0.30 & 0.86 & 1.39 & 2.74 & 10 & $\delta_{h}$ & 0.08 & 0.20 & 0.33 & 1.37 \\
\hline & $t_{N W}$ & {$[3.40]$} & {$[3.40]$} & [3.13] & [2.89] & & $t_{N W}$ & {$[0.63]$} & {$[0.42]$} & {$[0.38]$} & {$[0.54]$} \\
\hline & $t_{H}$ & $(3.32)$ & $(3.32)$ & $(3.30)$ & $(2.85)$ & & $t_{H}$ & $(0.80)$ & $(0.69)$ & $(0.73)$ & $(1.45)$ \\
\hline & $R^{2}$ & 0.09 & 0.18 & 0.24 & 0.27 & & $R^{2}$ & 0.01 & 0.01 & 0.01 & 0.02 \\
\hline
\end{tabular}


Table A.II. Predictive regressions of risk sharing on market integration: Sub-samples This table is similar to Table 3 but here we only present results for predictive regressions of risk sharing on market integration. The left panel shows results for the sub-sample from 1900 - 2012 whereas the right panel shows results for the sub-sample from $1946-2012$.

\begin{tabular}{|c|c|c|c|c|c|c|c|c|c|c|c|}
\hline & \multicolumn{5}{|c|}{ Dependent: Risk Sharing 1900 - 2012} & & \multicolumn{5}{|c|}{ Dependent: Risk Sharing 1946 - 2012} \\
\hline \multirow[b]{2}{*}{$k$} & & \multicolumn{4}{|c|}{ Forecast horizon $h$ in years } & \multirow[b]{2}{*}{$k$} & & \multicolumn{4}{|c|}{ Forecast horizon $h$ in years } \\
\hline & & 1 & 3 & 5 & 10 & & & 1 & 3 & 5 & 10 \\
\hline \multirow[t]{4}{*}{1} & $\gamma_{h}$ & 0.09 & 0.20 & 0.54 & 1.12 & 1 & $\gamma_{h}$ & 0.18 & 0.48 & 0.86 & 0.92 \\
\hline & $t_{N W}$ & {$[0.88]$} & {$[0.72]$} & {$[1.54]$} & {$[2.43]$} & & $t_{N W}$ & {$[1.39]$} & {$[1.33]$} & {$[1.97]$} & {$[3.93]$} \\
\hline & $t_{H}$ & $(0.94)$ & $(0.84)$ & $(1.60)$ & $(2.18)$ & & $t_{H}$ & $(1.46)$ & $(1.67)$ & $(1.89)$ & $(1.60)$ \\
\hline & $R^{2}$ & 0.01 & 0.01 & 0.04 & 0.07 & & $R^{2}$ & 0.03 & 0.06 & 0.13 & 0.14 \\
\hline \multirow[t]{4}{*}{2} & $\gamma_{h}$ & 0.10 & 0.27 & 0.69 & 1.35 & 2 & $\gamma_{h}$ & 0.27 & 0.72 & 1.36 & 1.20 \\
\hline & $t_{N W}$ & {$[0.87]$} & {$[0.88]$} & {$[1.74]$} & {$[2.54]$} & & $t_{N W}$ & {$[1.61]$} & {$[1.41]$} & {$[2.39]$} & {$[2.92]$} \\
\hline & $t_{H}$ & $(0.98)$ & (1.03) & (1.77) & $(2.33)$ & & $t_{H}$ & $(1.81)$ & (1.71) & $(2.11)$ & $(1.53)$ \\
\hline & $R^{2}$ & 0.01 & 0.02 & 0.06 & 0.10 & & $R^{2}$ & 0.05 & 0.09 & 0.21 & 0.15 \\
\hline \multirow[t]{4}{*}{5} & $\gamma_{h}$ & 0.16 & 0.62 & 1.21 & 1.81 & 5 & $\gamma_{h}$ & 0.42 & 1.45 & 2.44 & 1.59 \\
\hline & $t_{N W}$ & {$[1.50]$} & {$[2.16]$} & {$[2.94]$} & [2.98] & & $t_{N W}$ & {$[1.72]$} & {$[2.44]$} & {$[2.82]$} & {$[2.53]$} \\
\hline & $t_{H}$ & $(1.58)$ & $(2.13)$ & $(2.69)$ & $(2.70)$ & & $t_{H}$ & $(1.80)$ & $(2.17)$ & $(2.58)$ & $(1.36)$ \\
\hline & $R^{2}$ & 0.03 & 0.09 & 0.18 & 0.17 & & $R^{2}$ & 0.07 & 0.22 & 0.40 & 0.14 \\
\hline \multirow[t]{4}{*}{10} & $\gamma_{h}$ & 0.24 & 0.83 & 1.39 & 2.10 & 10 & $\gamma_{h}$ & 0.59 & 1.75 & 2.88 & 2.60 \\
\hline & $t_{N W}$ & {$[2.34]$} & {$[3.30]$} & {$[3.87]$} & {$[2.85]$} & & $t_{N W}$ & {$[1.94]$} & {$[2.17]$} & {$[2.68]$} & {$[2.63]$} \\
\hline & $t_{H}$ & $(2.41)$ & $(2.94)$ & $(3.12)$ & $(2.93)$ & & $t_{H}$ & $(2.05)$ & $(2.28)$ & $(2.50)$ & $(1.34)$ \\
\hline & $R^{2}$ & 0.06 & 0.15 & 0.21 & 0.22 & & $R^{2}$ & 0.08 & 0.15 & 0.24 & 0.21 \\
\hline
\end{tabular}


Table A.III. Market integration based on excess returns

The setup of this Table is identical to Table 3 but the proxy for financial market integration is based on excess stock returns. Excess stock returns are calculated as the local stock return minus the return of holding a short-term T-Bill.

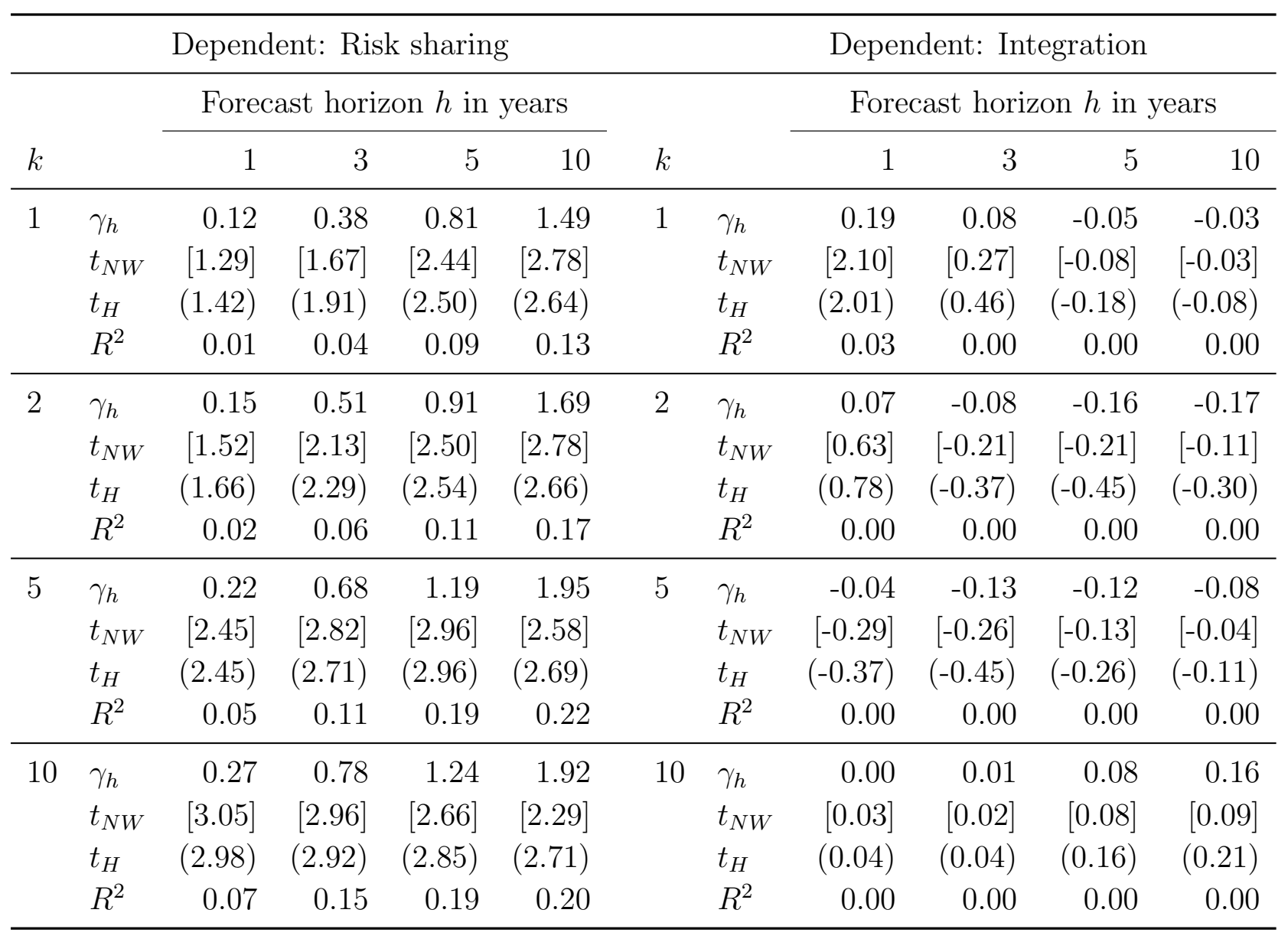


Table A.IV. Market Integration based on government bonds and T-Bills

The setup of this table is similar to Table 3 but we only show results for predictive regressions of consumption risk sharing on market integration. The left part of the table shows results for market integration measured as the cross-sectional standard deviation of government bond returns, whereas the right part shows results for integration measured by the cross-sectional standard deviation of T-Bill returns.

\begin{tabular}{|c|c|c|c|c|c|c|c|c|c|c|c|}
\hline \multicolumn{6}{|c|}{ Government Bonds } & \multicolumn{6}{|c|}{ T-Bills } \\
\hline & & \multicolumn{4}{|c|}{ Forecast horizon $h$ in years } & \multirow[b]{2}{*}{$k$} & & \multicolumn{4}{|c|}{ Forecast horizon $h$ in years } \\
\hline$k$ & & 1 & 3 & 5 & 10 & & & 1 & 3 & 5 & 10 \\
\hline \multirow[t]{4}{*}{1} & $\gamma_{h}$ & -0.02 & 0.10 & 0.38 & 1.17 & 1 & $\delta_{h}$ & -0.01 & 0.26 & 0.61 & 1.30 \\
\hline & $t_{N W}$ & {$[-0.20]$} & {$[0.38]$} & {$[0.95]$} & {$[1.56]$} & & & {$[-0.16]$} & {$[1.08]$} & {$[1.57]$} & [1.80] \\
\hline & $t_{H}$ & $(-0.22)$ & $(0.43)$ & $(1.08)$ & $(1.83)$ & & $t_{H}$ & $(-0.18)$ & $(1.16)$ & $(1.67)$ & $(2.04)$ \\
\hline & $R^{2}$ & -0.01 & -0.01 & 0.01 & 0.07 & & $R^{2}$ & -0.01 & 0.01 & 0.04 & 0.09 \\
\hline \multirow[t]{4}{*}{2} & $\gamma_{h}$ & 0.01 & 0.24 & 0.53 & 1.41 & 2 & $\delta_{h}$ & 0.06 & 0.42 & 0.77 & 1.50 \\
\hline & $t_{N W}$ & {$[0.12]$} & {$[0.86]$} & {$[1.24]$} & {$[1.80]$} & & & {$[0.66]$} & {$[1.68]$} & {$[1.94]$} & [2.03] \\
\hline & $t_{H}$ & $(0.13)$ & $(0.95)$ & $(1.33)$ & $(1.99)$ & & $t_{H}$ & $(0.71)$ & $(1.72)$ & $(1.93)$ & $(2.16)$ \\
\hline & $R^{2}$ & -0.01 & 0.01 & 0.03 & 0.11 & & $R^{2}$ & 0.00 & 0.04 & 0.08 & 0.12 \\
\hline \multirow[t]{4}{*}{5} & $\gamma_{h}$ & 0.11 & 0.43 & 0.88 & 1.78 & 5 & $\delta_{h}$ & 0.15 & 0.54 & 0.99 & 1.66 \\
\hline & $t_{N W}$ & {$[1.16]$} & {$[1.51]$} & [2.08] & {$[2.17]$} & & & {$[1.58]$} & {$[2.10]$} & {$[2.49]$} & [2.03] \\
\hline & $t_{H}$ & $(1.25)$ & $(1.54)$ & (2.11) & $(2.15)$ & & $t_{H}$ & (1.63) & $(2.00)$ & $(2.39)$ & (2.19) \\
\hline & $R^{2}$ & 0.01 & 0.04 & 0.11 & 0.17 & & $R^{2}$ & 0.01 & 0.07 & 0.13 & 0.15 \\
\hline \multirow[t]{4}{*}{10} & $\gamma_{h}$ & 0.23 & 0.70 & 1.14 & 1.71 & 10 & $\delta_{h}$ & 0.22 & 0.69 & 1.07 & 1.39 \\
\hline & $t_{N W}$ & {$[2.54]$} & [2.63] & {$[2.50]$} & [1.93] & & & [2.49] & {$[2.66]$} & {$[2.31]$} & [1.42] \\
\hline & $t_{H}$ & $(2.40)$ & (2.37) & $(2.32)$ & $(2.33)$ & & $t_{H}$ & $(2.39)$ & $(2.49)$ & $(2.36)$ & (2.04) \\
\hline & $R^{2}$ & 0.05 & 0.12 & 0.17 & 0.15 & & $R^{2}$ & 0.04 & 0.12 & 0.15 & 0.09 \\
\hline
\end{tabular}


Table A.V. Predictive regressions: Controlling for lagged dependent variables This table is similar to Table 3 but here we also include the (lagged) dependent variables as an additional predictor:

\begin{tabular}{|c|c|c|c|c|c|c|c|c|c|c|c|}
\hline \multirow[b]{3}{*}{$k$} & \multicolumn{5}{|c|}{ Dependent: Risk sharing } & \multicolumn{6}{|c|}{ Dependent: Market integration } \\
\hline & & \multicolumn{4}{|c|}{ Forecast horizon $h$ in years } & \multirow[b]{2}{*}{$k$} & & \multicolumn{4}{|c|}{ Forecast horizon $h$ in years } \\
\hline & & 1 & 3 & 5 & 10 & & & 1 & 3 & 5 & 10 \\
\hline \multirow[t]{7}{*}{1} & $\gamma_{h}$ & 0.10 & 0.26 & 0.63 & 1.29 & 1 & $\delta_{h}$ & 0.07 & -0.07 & -0.39 & -0.66 \\
\hline & $t_{N W}$ & {$[1.14]$} & {$[1.08]$} & {$[1.82]$} & {$[2.59]$} & & $t_{N W}$ & {$[0.92]$} & {$[-0.28]$} & {$[-0.83]$} & {$[-0.69]$} \\
\hline & $t_{H}$ & $(1.14)$ & $(1.24)$ & $(1.92)$ & $(2.42)$ & & $t_{H}$ & $(0.77)$ & $(-0.38)$ & $(-1.55)$ & $(-1.75)$ \\
\hline & $\rho_{h}$ & 0.19 & 0.40 & 0.49 & 0.50 & & $\rho_{h}^{\prime}$ & 0.51 & 1.27 & 1.89 & 3.00 \\
\hline & $t_{N W}$ & {$[2.50]$} & {$[3.00]$} & {$[1.88]$} & {$[1.29]$} & & $t_{N W}$ & {$[7.64]$} & {$[6.70]$} & {$[5.11]$} & {$[3.40]$} \\
\hline & $t_{H}$ & $(2.43)$ & $(2.38)$ & $(2.04)$ & $(1.54)$ & & $t_{H}$ & $(5.65)$ & $(6.35)$ & $(5.96)$ & $(5.42)$ \\
\hline & $R^{2}$ & 0.19 & 0.40 & 0.49 & 0.50 & & $R^{2}$ & 0.51 & 1.27 & 1.89 & 3.00 \\
\hline \multirow[t]{7}{*}{2} & $\gamma_{h}$ & 0.09 & 0.34 & 0.75 & 1.51 & 2 & $\delta_{h}$ & -0.02 & -0.24 & -0.65 & -0.95 \\
\hline & $t_{N W}$ & {$[0.97]$} & [1.37] & [1.99] & [2.73] & & $t_{N W}$ & {$[-0.23]$} & {$[-0.88]$} & {$[-1.16]$} & {$[-0.85]$} \\
\hline & $t_{H}$ & $(0.99)$ & $(1.48)$ & $(2.03)$ & $(2.47)$ & & $t_{H}$ & $(-0.20)$ & $(-1.07)$ & $(-1.97)$ & $(-1.91)$ \\
\hline & $\rho_{h}$ & 0.20 & 0.40 & 0.48 & 0.49 & & $\rho_{h}^{\prime}$ & 0.52 & 1.30 & 1.94 & 3.08 \\
\hline & $t_{N W}$ & {$[2.51]$} & {$[3.03]$} & {$[1.85]$} & [1.37] & & $t_{N W}$ & {$[7.82]$} & {$[6.88]$} & {$[5.30]$} & {$[3.53]$} \\
\hline & $t_{H}$ & $(2.50)$ & $(2.37)$ & (1.98) & $(1.50)$ & & $t_{H}$ & $(5.74)$ & $(6.41)$ & $(6.03)$ & $(5.50)$ \\
\hline & $R^{2}$ & 0.20 & 0.40 & 0.48 & 0.49 & & $R^{2}$ & 0.52 & 1.30 & 1.94 & 3.08 \\
\hline \multirow[t]{7}{*}{5} & $\gamma_{h}$ & 0.15 & 0.57 & 1.12 & 1.87 & 5 & $\delta_{h}$ & -0.06 & -0.29 & -0.56 & -0.57 \\
\hline & $t_{N W}$ & {$[1.73]$} & {$[2.26]$} & {$[2.73]$} & [2.84] & & $t_{N W}$ & {$[-0.73]$} & {$[-0.84]$} & {$[-0.83]$} & {$[-0.42]$} \\
\hline & $t_{H}$ & (1.67) & $(2.18)$ & $(2.79)$ & $(2.69)$ & & $t_{H}$ & $(-0.62)$ & $(-1.08)$ & $(-1.36)$ & $(-0.91)$ \\
\hline & $\rho_{h}$ & 0.18 & 0.34 & 0.36 & 0.30 & & $\rho_{h}^{\prime}$ & 0.53 & 1.28 & 1.88 & 2.92 \\
\hline & $t_{N W}$ & {$[2.16]$} & {$[2.48]$} & {$[1.39]$} & {$[0.85]$} & & $t_{N W}$ & {$[8.00]$} & {$[6.28]$} & {$[4.52]$} & {$[2.96]$} \\
\hline & $t_{H}$ & $(2.19)$ & (1.98) & $(1.51)$ & $(0.91)$ & & $t_{H}$ & $(5.80)$ & $(6.29)$ & $(5.88)$ & $(5.20)$ \\
\hline & $R^{2}$ & 0.18 & 0.34 & 0.36 & 0.30 & & $R^{2}$ & 0.53 & 1.28 & 1.88 & 2.92 \\
\hline \multirow[t]{7}{*}{10} & $\gamma_{h}$ & 0.23 & 0.70 & 1.20 & 1.93 & 10 & $\delta_{h}$ & -0.02 & -0.09 & -0.16 & -0.05 \\
\hline & $t_{N W}$ & {$[2.61]$} & {$[2.76]$} & {$[2.75]$} & {$[2.62]$} & & $t_{N W}$ & {$[-0.34]$} & {$[-0.30]$} & {$[-0.29]$} & {$[-0.05]$} \\
\hline & $t_{H}$ & $(2.52)$ & $(2.68)$ & $(2.82)$ & $(2.65)$ & & $t_{H}$ & $(-0.26)$ & $(-0.31)$ & $(-0.36)$ & $(-0.07)$ \\
\hline & $\rho_{h}$ & 0.12 & 0.30 & 0.34 & 0.58 & & $\rho_{h}^{\prime}$ & 0.56 & 1.35 & 1.95 & 2.99 \\
\hline & $t_{N W}$ & {$[1.36]$} & {$[2.03]$} & {$[1.25]$} & {$[1.85]$} & & $t_{N W}$ & {$[8.26]$} & {$[6.58]$} & {$[4.54]$} & {$[2.79]$} \\
\hline & $t_{H}$ & (1.48) & (1.74) & (1.34) & (1.62) & & $t_{H}$ & $(5.93)$ & $(6.33)$ & $(5.83)$ & $(5.19)$ \\
\hline & $R^{2}$ & 0.07 & 0.16 & 0.20 & 0.24 & & $R^{2}$ & 0.30 & 0.29 & 0.26 & 0.20 \\
\hline
\end{tabular}



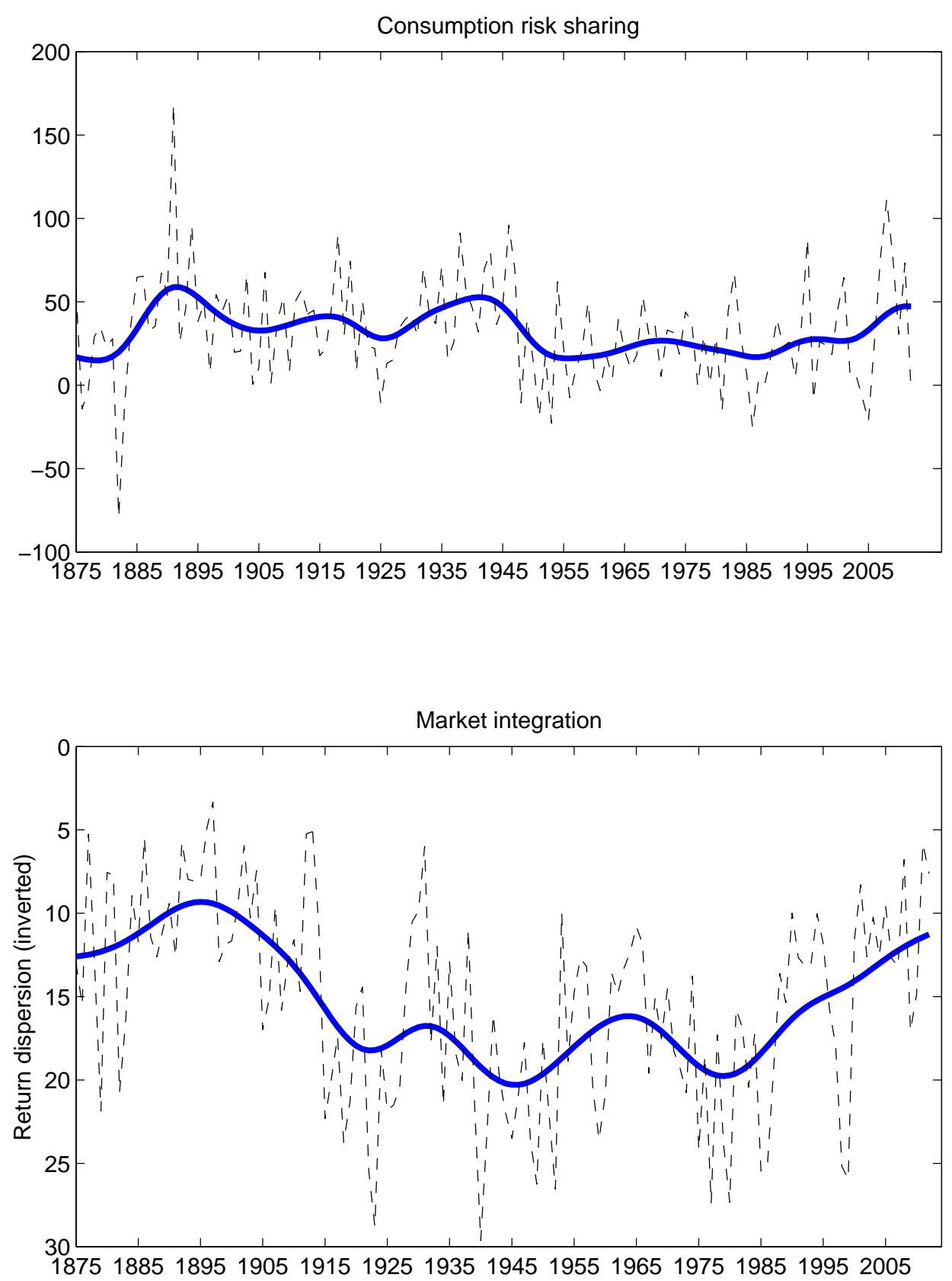

Figure A.1. Smoothed and unsmoothed estimates of risk sharing and market integration

This figure shows the smoothed (blue solid lines) and unsmoothed (black dashed lines) timeseries of our estimates of consumption risk sharing (upper panel) and market integration (lower panel). The smoothed series in the upper panel corresponds to Figure 1 whereas the smoothed series in the lower panel corresponds to Figure 3. 


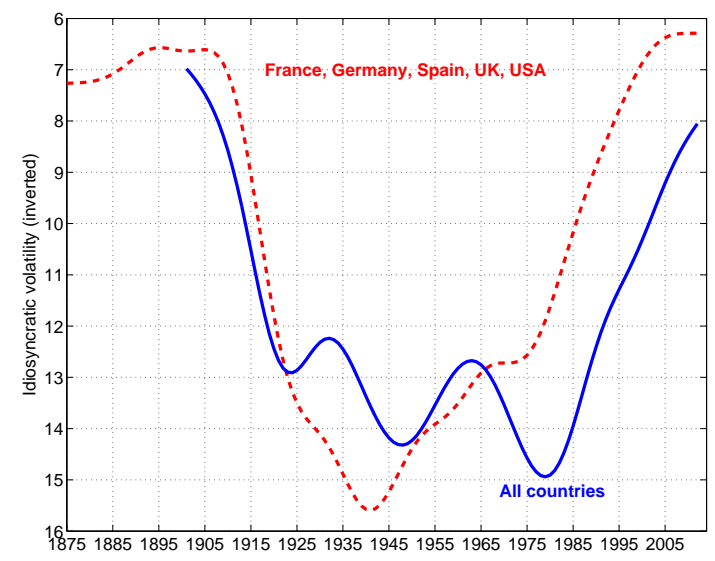

(a) Idiosyncratic volatility

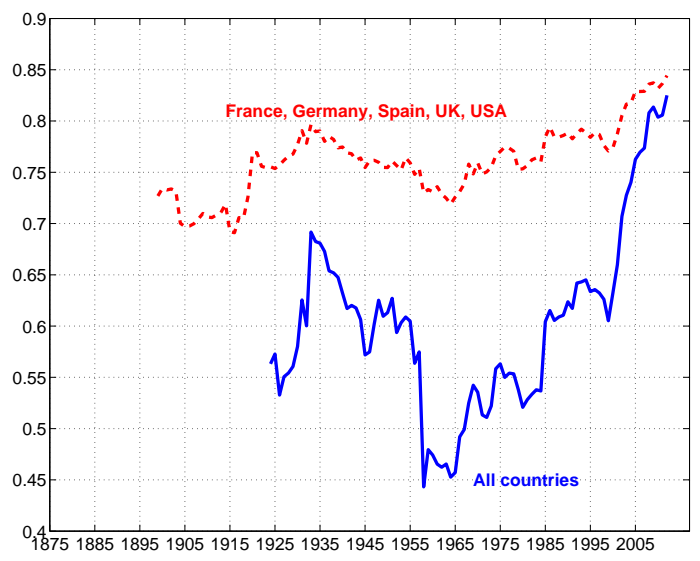

(b) Common factors

Figure A.2. Stock market integration: Alternative measures

This figure two alternative measures of market integration. Panel (a) shows a measure of market integration similar to Figure 3 in the main text but here we average across countries' idiosyncratic volatilities - obtained from a World CAPM estimated for each individual country over the full sample period. Panel (b) shows average $R^{2} \mathrm{~s}$ (across countries) for rolling windows of 25 years (starting in 1875). For each sub-sample, we factorize the covariance matrix of stock returns and form "common factor" portfolios based on the eigenvectors of the decomposition (such that our common factors account for at least $80 \%$ of return (co)variances). We then regress individual country's stock returns on these common factors and compute the $R^{2}$. The plot is based on the average $R^{2}$ across countries for each sub-sample. The figures shows regression $R^{2}$ s (i) for the full sample period but only for five countries (dashed line) for which data are available for the full sample period and (ii) for the full set of all countries but a sample that starts in 1925 when many countries enter the sample. 